\title{
Assessment of Conditions for Implementing Information Technology in a Warehouse System: A Novel Fuzzy PIPRECIA Method
}

\author{
Željko Stević ${ }^{1, * \mathbb{C}}$, Željko Stjepanović $^{1}$, Zdravko Božičković ${ }^{1}$, Dillip Kumar Das ${ }^{2}$ and \\ Dragiša Stanujkić ${ }^{3}$ (1) \\ 1 Faculty of Transport and Traffic Engineering Doboj, University of East Sarajevo, Vojvode Mišića 52, \\ 74000 Doboj, Bosnia and Herzegovina; zeljko.stjepanovic@sf.ues.rs.ba (Ž.S.); \\ zdravko.bozickovic@sf.ues.rs.ba (Z.B.) \\ 2 Department of Civil Engineering, Central University of Technology, Free State, Bloemfontein 9300, \\ South Africa; ddas@cut.ac.za \\ 3 Department of Management, Technical Faculty in Bor, University of Belgrade, Vojske Jugoslavije 12, \\ 19210 Bor, Serbia; dstanujkic@tfbor.bg.ac.rs \\ * Correspondence: zeljkostevic88@yahoo.com or zeljko.stevic@sf.ues.rs.ba
}

Received: 17 October 2018; Accepted: 29 October 2018; Published: 2 November 2018

\begin{abstract}
The application of information technology in all areas represents a significant facilitation of all business processes and activities. A competitive business system is hardly imaginable without adequate information technology. Therefore, this paper evaluates the conditions for the implementation of barcode technology in a warehouse system of a company for the manufacture of brown paper. SWOT (Strengths, Weaknesses, Opportunities, Threats) matrix was formed with a total of 27 elements based on which the benefits of the implementation of barcode technology in the warehouse system need to be analysed. For this purpose, a new fuzzy PIPRECIA (PIvot Pairwise RElative Criteria Importance Assessment) method has been developed to evaluate all elements in SWOT matrix. In addition, a part of the new developed approach includes new fuzzy scales for criterion assessment that are adapted to the methodology required by the fuzzy PIPRECIA method. To determine the consistency of the method, Spearman and Pearson correlation coefficients are applied. The results obtained in this study show that weaknesses are most noticeable in the current system. By implementing barcode technology, it is possible to create opportunities defined in SWOT matrix, which, in a very efficient way, allow elimination of the current weaknesses of the system.
\end{abstract}

Keywords: fuzzy PIPRECIA; barcode technology; SWOT; warehouse system; multi-criteria decision making (MCDM)

\section{Introduction}

A logistics network that implies the linkage of adequate infrastructure, construction facilities, logistics centres, properties and processes in them is an indispensable factor for the success of a global supply chain. A warehouse system in a complete logistics network plays an important role and in one way represents a place where raw materials, materials, semi-products or finished goods are collected and stored, which are later included in other processes. As a warehouse system represents a timely transformation of goods, after the expiration of the anticipated or required timeframe for the preservation of material flows, they are further dispatched to different locations where a demand for them is shown. Storage systems are linked and often an irreplaceable factor in a logistics chain. In a manufacturing process, situations when raw materials or materials are immediately included in a manufacturing process are rare and practically they are always for a certain period in a sleeping 
mode or in a warehouse. The situation is similar with finished products and semi-finished products. In order to achieve a competitive market position, it is necessary to rationalize logistics activities and processes. A warehouse appears as one of the subsystems in which rationalization is possible and which as a special logistics subsystem besides transportation represents the biggest cause of logistical costs and thus there is constant search for potential places for savings in these subsystems. Compared to its former static function, today's warehouse represents a dynamic system in which the movement of goods is dominant. Therefore, in this paper, the emphasis is on one of the warehouse systems of Natron-Hayat (http:/ / www.natron-hayat.ba/index.php), one of the largest companies in Bosnia and Herzegovina.

"Work unit-Warehouse," which includes the warehouse of technical material and the reception warehouse, is a part of Natron-Hayat and a very important factor in the entire company. All necessary material for uninterrupted manufacturing process is a part of the warehouse of technical material. In addition, this warehouse represents an irreplaceable factor regarding spare parts for a variety of machines and an important factor in it is its organization, where each item must be stored in an appropriate place and clearly marked. The reason for this is undisturbed removal of material from the warehouse and the acceleration of the process. In order to accelerate and facilitate the process of removing goods from the warehouse, it is necessary to consider the conditions for introducing barcode technology to the warehouse. The use of barcode technology has revolutionized a logistical approach to production and distribution. Without applying barcode technology, many tasks that are more complex would be practically difficult to accomplish. Advantages in business provided by barcode technology are many and some of them are as follows: barcode technology shortens the time of work realization in the Reception Warehouse and the Warehouse of Technical Material; it eliminates the possibility of human errors in warehousing; barcode technology transfers all information accurately and precisely into the system; it shortens the time of supplementing inventory and so forth.

On the other hand, modern information technology plays a very important role in achieving defined strategic goals, which accelerates and facilitates the flow of all logistics processes and activities. One of the aims of this study is to determine the possibilities for implementing barcode technology in the warehouse of technical material and the reception warehouse of Natron-Hayat by developing an integrated model. Integration implies the application of SWOT analysis [1] with a new multi-criteria decision making Fuzzy PIPRECIA method, which is a part of the developed model. In addition to the aforementioned aim that has a practical contribution, this paper has several aims from the aspect of scientific contribution. The first of the scientific aims is to develop a new fuzzy PIPRECIA method that allows the determination of weighting criterion values by considering all the necessary elements for more objective calculation of criterion significance. The second scientific aim of the work refers to defining new fuzzy scales for criterion assessment that have been deliberately developed to take full advantage of the benefits offered by the Fuzzy PIPRECIA method. The third aim of this paper is to bridge the gap that currently exists for certain problems of multi-criteria decision-making when a large number of decision-makers are involved. The developed method makes it possible to determine the significance of criteria without prior sorting the criteria by importance.

In addition to introductory considerations, the structure of this work includes five more sections. The Section 2 presents a review of the literature throughout three parts. The Section 3 presents the methodology applied in this research. The basic items of SWOT analysis and basic operations on fuzzy numbers have been presented and the development of new fuzzy scales for criterion assessment and the development of new fuzzy PIPRECIA method have been performed. The assessment of the conditions for the implementation of barcode technology has been carried out in the Section 4 . Processes in storage systems have been presented and SWOT analysis has been formed and explained in detail. Subsequently, the fuzzy PIPRECIA method has been applied to assess the elements of SWOT matrix. Section 5 is a sensitivity analysis and discussion of the obtained results. This section presents the ranks of all criteria and calculates Spearman and Pearson correlation coefficients. The Section 6 provides conclusions with the guidelines for future research. 


\section{Literature Review}

Decision making on complex socio-economic problems including that business-related decisions requires appropriate and reliable decision support system. Evidences from literature show that increase in the complexity of decisions makes it difficult for the decision-makers to identify management alternatives that maximize all decision criteria [2-4]. Planning and decision making requires a multi-objective approach and analytical methods that examine trade-offs, consider multiple political, economic, environmental and social dimensions, reduce conflicts, in an optimizing framework [2]. In other words, decision problems depend on a set of criteria that include attributes and objectives and should possess some properties to adequately represent the multi-criteria [5], which can be defined by the interested literature, analytical study and opinions [6-9] and must be comprehensive and measurable $[4,5]$.

Multi-Criteria Decision Making (MCDM) tools are considered as the established methods to aid decision makers in taking apposite decisions [10-12] and their applications are observed to growing in popularity in many fields that includes but not limited to business management, logistics, supply chain, energy, urban development, waste management and so forth. [13-17]. MCDM methods generally assist in decision making mainly through evaluation, comparison and selecting initiatives for example technologies, strategies and so forth, in relation to the achieved or planned effects resulting from their introduction in the context or environment [11,18]. However, it is evidenced that many inappropriate selection choices (such as technology, strategies, etc.) are still being made by the decision makers leading to unreliable decisions, consequently which there is a growing argument for the need for a wider uptake of MCDM methods to address this problem [12,19].

In this regard, integrated and hybrid MCDM models were developed used in different contexts to aid and improve the decision-making process. Numerous examples of the application of different MCDM methods, in combination with other methods, in a conventional form or in the fuzzy environment are evidenced in the main stream literature [20]. For example, fuzzy logic has been integrated with Analytical Network Process (ANP), one of the widely used MCDM methods to improve the process of evaluation and is found to be most appropriate methodological solution because of its superiority in addressing the complex network structure [21-24].

\subsection{The Application of Fuzzy MCDM Method in Storage Systems}

Fuzzy MCDM methods have been used to solve many problems in different areas. The number of references regarding the use of fuzzy MCDM methods for solving problems related to storage systems is following. Fuzzy Analytic Hierarchy Process (AHP) is used for the evaluation of hydrogen storage systems in the automotive industry [25]. In order to improve the performance of their supply chain, companies have to choose an adequate warehouse location that will suit multiple needs and requirements. The combination of fuzzy AHP and fuzzy TOPSIS (Technique for Order of Preference by Similarity to Ideal Solution) methods was applied in [26] for optimum selection of five potential storage locations. The importance and impact of warehouses on the complete efficiency of supply chains are confirmed by following studies [27-30]. Ashrafzadeh et al. [27] emphasize that the choice of warehouse location is of strategic importance for many companies and they use the fuzzy TOPSIS method for these purposes. The significance of an adequate warehouse location in a supply chain of hazardous substances reduces the risk of negative effects as confirmed by research [28], where the authors used a fuzzy MULTIMOORA (MULTIplicative form with Multi-Objective Optimization Ratio Analysis) method for the location selection. The combination of MCDM methods in integration with fuzzy logic was also applied in [30] to determine a warehouse location. The authors used fuzzy TOPSIS, fuzzy SAW (Simple Additive Weightingand) fuzzy MOORA (Multi-Objective Optimization Ratio Analysis) methods, while Emec and Akkaya [31] applied a stohastical AHP and fuzzy VIKOR (VlseKriterijumska Optimizacija I Kompromisno Resenje) for the same purpose.

Fuzzy multi-criteria decision-making is also used for other tasks related to storage systems. Echo Saputro and Daneshvar Rouyendegh [32] carried out the evaluation and selection of material 
handling equipment in a warehouse using a combined fuzzy AHP and fuzzy TOPSIS method. One of studies [33], similar to the study carried out in this paper, refers to the assessment of barcode application or RFID (Radio-frequency identification) technology in a storage system which is in the development of logistics has a tendency to grow ([34]. For this purpose, the fuzzy AHP method was applied. In modern manufacturing industries, machines are connected and shared within the manufacturing network. Thus, information technologies are widely applied in the smart factory, among which RFID (Radio Frequency Identification) devices are the most important elements to collect real-time data and track important objects [35].

\subsection{The Application of Fuzzy MCDM Methods in the Field of Information Technology}

The use of fuzzy MCDM methods is more intensive in Information Technology, where these methods are most commonly used for software selection and the following examples can be stated as more important: selection of ERP software [36,37], selection of software in manufacturing industry [38,39], selection of software development strategy [40] and selection of e-learning system [41]. There are also numerous examples of web site evaluation using a fuzzy MCDM method, such as: [42-44].

Efficient logistics and supply chain management are enabled using efficient information technology (IT), so in Reference [45], the identification and evaluation of mobile logistics tool was carried out. In their paper, [46] addressed the logistics information technology evaluation and selection criteria for practitioners and proposed a new multi-attribute decision-making methodology, hierarchical fuzzy TOPSIS, for the problem.

\subsection{The Application of Integrated SWOT-MCDM Models}

Also, SWOT analysis has found to be an efficient tool in defining the management plans and characterization of the performance measures in the socio-economic and industrial systems and has been a very successful tool for understanding how a system is performing (for example a company [47-49]. It maximizes strengths and opportunities and minimizes threats and weaknesses of a system and identifies the conditions of the system according to these characteristics. For example, it is an important support tool for decision-making and is commonly used as a means to systematically analyse an organization's internal and external environments [37]. SWOT analysis is often used both for determining the strategic position of the company and getting the real picture in deciding which strategy suits the company better. Besides, it is used to examine whether the generated strategies (business scenarios) would enable the company to apply it appropriately [21]. However, largely, SWOT analysis focuses on how the opportunities will be assessed and how to eliminate the threats; in other words, despite its strengths and utility value it is generally the first stage of a large-scale study. However, its application has been significantly improved by extending its ability to quantify the SWOT factors, Lately, it has been integrated with MCDM methods, which has expanded its application for example to develop ranking strategies and enable decision-makers to make objective decisions under conditions of uncertainty $[21,24,50]$.

Thus, MCDM and SWOT have their strengths and limitations, however, hybrid and integrated MCDM and SWOT models are evidenced to have offered more objective, robust and reliable performances in decision making. Although, a number of studies have been made integrating MCDM and SWOT $[21,24,50]$, studies relating to the context of this study are found to be scarce. Therefore, this study will contribute to expand the integration of MCDM and SWOT model to the field of logistics and barcoding, which perhaps will enable more realistic and reliable decision making.

\section{Methods}

Figure 1 shows a methodology, that is, a course of research consisting of three phases with a total of 12 steps taken. 


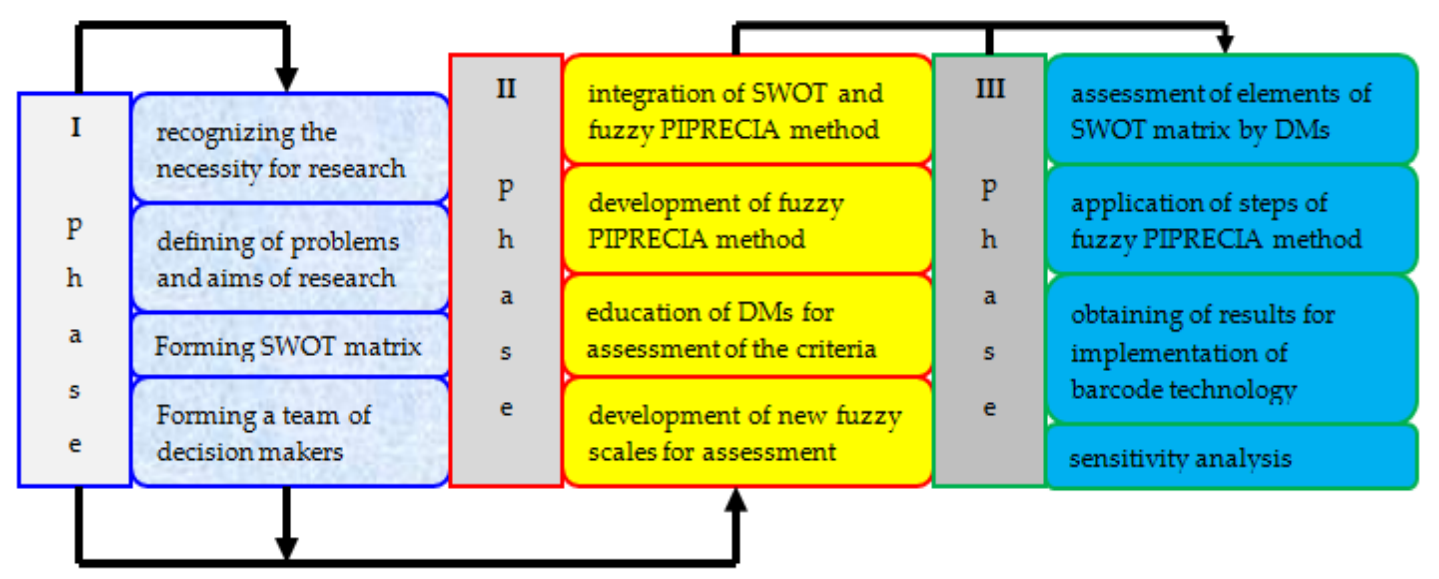

Figure 1. Proposed methodology of research.

Figure 1 shows a complete course of research that implies assessing the conditions for implementing barcode technology in a warehouse system with the development of a new fuzzy PIPRECIA method. The initial phase involves recognizing the necessity for research in the first step, after which the defining of problems and aims of research has been performed in the second step. In order to enable adequately access to the assessment of the conditions for evaluating the implementation of this information technology in the warehouse system of Natron-Hayat, SWOT analysis was carried out. The SWOT matrix of 27 elements was formed, representing the third step of this phase. The final step of the first phase of research is the formation of a decision-making team that implies the managers of the company's warehouse system in which barcode technology needs to be implemented. In order to assess criteria adequately by decision-makers, new fuzzy scales, which are methodologically specific and related to the development of the fuzzy PIPRECIA method, have been formed. In the first step of the second phase, two new fuzzy scales have been developed, which are explained in more detail below in a fuzzy PIPRECIA method algorithm. The second step is specific for the formation of such models as it relates to the education of decision-makers for assessment of criteria. Since it is about extending the PIPRECIA method [51] with fuzzy numbers and since new evaluation scales are defined and have not been used before, it is necessary to explain to the decision-makers the way how they are applied. Since a part of the research team is located in a town near the company, they have briefly lectured on new scales to provide an adequate assessment at the very start and eventually objective results that will help the company. The third step of the second phase is the development of a new approach with its steps explained in detail below. The fourth step of the second phase is the integration of SWOT matrix and fuzzy PIPRECIA method. The third phase begins with the assessment of criteria in the first step, so that the second step includes an analytical part that implies data processing and the calculation of results. Finally, a sensitivity analysis was performed by calculating correlation coefficients.

\subsection{SWOT Analysis}

SWOT analysis was created by Stanford University researchers within the project that aimed to determine what was going wrong with corporate planning, as well as to create a new management change system. What is good in the present, they called Satisfactory; what is good in the future, they called Opportunity; bad in the present-a Fault and bad in the future-a Threat. The acronym was S-O-F-T. It later changed to SWOT [1]. The simplest method for the analysis of environment is SWOT analysis and represents a qualitative analytical method that throughout four factors attempts to present strengths, weaknesses, opportunities and threats of a certain phenomenon or situation in a subject of analysis. The basic idea of SWOT analysis according to [52] is to determine internal strengths and weaknesses, as well as external threats and opportunities. In this way, continuous progress and development are achieved and thus competitive advantage too. It can be used when it 
comes to creating a company's development strategy or analysing competitors and market positions. It is desirable for SWOT analysis to be performed by organization managers who are well acquainted with it but in cooperation with external consultants (who have special analytical skills and independent viewpoint) for objectivity. By analysing the environment throughout a detailed list of favourable and unfavourable factors, it stimulates research effort and provides reality in defining strategies. SWOT analysis is quick, simple and according to [53], it can be adapted as a factor identification tool that influences organization's activities and provides solutions for the development of a future strategy. SWOT analysis is an analytical framework for management to obtain relevant information about the organization itself and the environment in which it operates at the moment and it will operate in the future with the purpose of identifying strategic opportunities and threats in the environment and their own strategic strengths and weaknesses. It enables management to develop a strategy based on relevant organization and environment information. SWOT analysis is based on the assumption that the organization will achieve maximum strategic success by maximizing its own strengths and opportunities in the environment while minimizing threats and weaknesses, that is, by the best use of internal strengths using the opportunities from the environment. An important assumption is an analysis of the accordance of internal and external factors, that is, the determination of their implications for the strategy. In fact, internal strengths and weaknesses should be seen in a context of external opportunities and threats and vice versa.

\subsection{Operations on Fuzzy Numbers}

A fuzzy number $\bar{A}$ on $\mathrm{R}$ to be a TFN if its membership function $\mu_{\bar{A}}(x): \mathrm{R} \rightarrow[0,1]$ is equal to following Equation (1):

$$
\mu_{\bar{A}}(x)=\left\{\begin{array}{cc}
\frac{x-l}{m-l} & l \leq x \leq m \\
\frac{u-x}{u-m} & m \leq x \leq u \\
0 & \text { otherwise }
\end{array} .\right.
$$

From Equation (1), $l$ and $u$ mean the lower and upper bounds of the fuzzy number $\bar{A}$ and $m$ is the modal value for $\bar{A}$. The TFN can be denoted by $\bar{A}=(l, m, u)$.

The operational laws of TFN $\bar{A}=\left(l_{1}, m_{1}, u_{1}\right)$ and $\bar{A}=\left(l_{2}, m_{2}, u_{2}\right)$ are displayed as following equations.

Addition: $\bar{A}=\left(l_{1}, m_{1}, u_{1}\right)$

$$
\overline{A_{1}}+\overline{A_{2}}=\left(l_{1}, m_{1}, u_{1}\right)+\left(l_{2}, m_{2}, u_{2}\right)=\left(l_{1}+l_{2}, m_{1}+m_{2}, u_{1}+u_{2}\right) .
$$

Multiplication:

$$
\overline{A_{1}} \times \overline{A_{2}}=\left(l_{1}, m_{1}, u_{1}\right) \times\left(l_{2}, m_{2}, u_{2}\right)=\left(l_{1} \times l_{2}, m_{1} \times m_{2}, u_{1} \times u_{2}\right) .
$$

Subtraction:

$$
\overline{A_{1}}-\overline{A_{2}}=\left(l_{1}, m_{1}, u_{1}\right)-\left(l_{2}, m_{2}, u_{2}\right)=\left(l_{1}-u_{2}, m_{1}-m_{2}, u_{1}-l_{2}\right) .
$$

Division:

$$
\frac{\overline{A_{1}}}{\overline{A_{2}}}=\frac{\left(l_{1}, m_{1}, u_{1}\right)}{\left(l_{2}, m_{2}, u_{2}\right)}=\left(\frac{l_{1}}{u_{2}}, \frac{m_{1}}{m_{2}}, \frac{u_{1}}{l_{2}}\right)
$$

Reciprocal:

$$
{\overline{A_{1}}}^{-1}=\left(l_{1}, m_{1}, u_{1}\right)^{-1}=\left(\frac{1}{u_{1}}, \frac{1}{m_{1}}, \frac{1}{l_{1}}\right) .
$$




\subsection{A Novel Fuzzy PIvot Pairwise RElative Criteria Importance Assessment-Fuzzy PIPRECIA Method}

The PIPRECIA method in a crisp form has been developed in Reference [51]. The basic advantage of the PIPRECIA method is that it allows criteria to be evaluated without their prior sorting by importance, which is not the case with the fuzzy SWARA method. Today, most of the problems of multi-criteria decision-making are being solved by applying group decision-making. In such cases, especially with an increase in the number of decision-makers involved in the fuzzy model, PIPRECIA achieves its advantages. The fuzzy PIPRECIA method consists of 11 steps that are shown below.

Step 1. Forming the required benchmarking set of criteria and forming a decision-making team. Sorting the criteria according to marks from the first to the last, this means that they need to be sorted unclassified. Therefore, in this step, their significance does not play any role.

Step 2. In order to determine the relative importance of criteria, each decision-maker individually evaluates pre-sorted criteria by starting from the second criterion, Equation (7).

$$
\overline{s_{j}^{r}}=\left\{\begin{array}{lll}
>\overline{1} & \text { if } & C_{j}>C_{j-1} \\
=\overline{1} & \text { if } & C_{j}=C_{j-1} \\
<\overline{1} & \text { if } & C_{j}<C_{j-1}
\end{array} .\right.
$$

$\overline{s_{j}^{r}}$ denotes the assessment of criteria by a decision-maker $r$.

In order to obtain a matrix $\overline{s_{j}}$, it is necessary to perform the averaging of matrix $\overline{s_{j}^{r}}$ using a geometric mean. Decision-makers evaluate criteria by applying new defined scales in Tables 1 and 2.

Table 1. Scale 1-2 for the assessment of criteria.

\begin{tabular}{|c|c|c|c|c|c|c|}
\hline \multirow[t]{2}{*}{ Linguistic Scale } & & \multicolumn{5}{|c|}{ Fuzzy Number } \\
\hline & & & 1 & $\mathrm{~m}$ & $\mathrm{u}$ & DFV \\
\hline Almost equal value & & 1 & 1.000 & 1.000 & 1.050 & 1.008 \\
\hline Slightly more significant & & 2 & 1.100 & 1.150 & 1.200 & 1.150 \\
\hline Moderately more significant & & 3 & 1.200 & 1.300 & 1.350 & 1.292 \\
\hline More significant & Scale 1-2 & 4 & 1.300 & 1.450 & 1.500 & 1.433 \\
\hline Much more significant & & 5 & 1.400 & 1.600 & 1.650 & 1.575 \\
\hline Dominantly more significant & & 6 & 1.500 & 1.750 & 1.800 & 1.717 \\
\hline Absolutely more significant & & 7 & 1.600 & 1.900 & 1.950 & 1.858 \\
\hline
\end{tabular}

Table 2. Scale $0-1$ for the assessment of criteria.

\begin{tabular}{|c|c|c|c|c|c|}
\hline \multicolumn{5}{|c|}{ Fuzzy Number } & \multirow[t]{2}{*}{ Linguistic Scale } \\
\hline \multirow{8}{*}{ Scale $0-1$} & 1 & $\mathrm{~m}$ & $\mathrm{u}$ & DFV & \\
\hline & 0.667 & 1.000 & 1.000 & 0.944 & weakly less significant \\
\hline & 0.500 & 0.667 & 1.000 & 0.694 & moderately less significant \\
\hline & 0.400 & 0.500 & 0.667 & 0.511 & less significant \\
\hline & 0.333 & 0.400 & 0.500 & 0.406 & really less significant \\
\hline & 0.286 & 0.333 & 0.400 & 0.337 & much less significant \\
\hline & 0.250 & 0.286 & 0.333 & 0.288 & dominantly less significant \\
\hline & 0.222 & 0.250 & 0.286 & 0.251 & absolutely less significant \\
\hline
\end{tabular}

The second and third steps of the developed method are in close dependence and new fuzzy scales are defined to meet the second and third step of the fuzzy PIPRECIA method. If the nature of fuzzy number operations is taken into account along with the fact that, in the third step, the values $\overline{s_{j}}$ are subtracted from the number two, it is required to define these scales. It is important to note that by defining these scales, the appearance of number two is avoided, which in the case of calculation could cause difficulties and wrong results (for example, if number two appears we can have the situation that $l, m$ or $u$ of the fuzzy number for $k j$ is zero, so we cannot continue further). Therefore, no other fuzzy scales could be used that have been previously developed but only the scales defined in this paper. 
When the criterion is of greater importance in relation to the previous one, assessment is made using the above scale in Table 1. In order to make decision-makers easier to evaluate the criteria, the table shows the defuzzified value (DFV) for each comparison.

When the criterion is of less importance compared to the previous one, assessment is made using the above-mentioned scale in Table 2.

Step 3. Determining the coefficient $\overline{k_{j}}$

$$
\overline{k_{j}}=\left\{\begin{array}{cll}
=\overline{1} & \text { if } & j=1 \\
2-\overline{s_{j}} & \text { if } & j>1
\end{array} .\right.
$$

Step 4. Determining the fuzzy weight $\overline{q_{j}}$

$$
\overline{q_{j}}=\left\{\begin{array}{lll}
=\overline{1} & \text { if } & j=1 \\
\overline{\bar{q}_{j-1}} & \text { if } & j>1
\end{array} .\right.
$$

Step 5. Determining the relative weight of the criterion $\overline{w_{j}}$

$$
\overline{w_{j}}=\frac{\overline{q_{j}}}{\sum_{j=1}^{n} \overline{q_{j}}} .
$$

In the following steps, the inverse methodology of fuzzy PIPRECIA method needs to be applied. Step 6. Performing the assessment of above-defined applying scale but this time starting from a penultimate criterion.

$$
\overline{s_{j}^{r}} I=\left\{\begin{array}{lll}
>\overline{1} & \text { if } & C_{j}>C_{j+1} \\
=\overline{1} & \text { if } & C_{j}=C_{j+1} \\
<\overline{1} & \text { if } & C_{j}<C_{j+1}
\end{array} .\right.
$$

$\overline{s_{j}^{r}}$ / denotes the assessment of criteria by a decision-maker $r$.

It is again necessary to perform the averaging of matrix $\overline{s_{j}^{r}}$ by applying a geometric mean.

Step 7. Determining the coefficient $\overline{k_{j}}$,

$$
\overline{k_{j}} \prime=\left\{\begin{array}{cll}
=\overline{1} & \text { if } & j=n \\
2-\overline{s_{j}} \prime & \text { if } & j>n
\end{array}\right.
$$

$n$ denotes a total number of criteria. Specifically, in this case, it means that the value of the last criterion is equal to the fuzzy number one.

Step 8. Determining the fuzzy weight $\overline{q_{j}}$

$$
\overline{q_{j}} \prime=\left\{\begin{array}{lll}
=\overline{1} & \text { if } & j=n \\
\overline{\bar{q}_{j+1}^{\prime}} & \text { if } & j>n
\end{array}\right.
$$

Step 9. Determining the relative weight of the criterion $\overline{w_{j}}$ '

$$
\overline{w_{j}} \prime=\frac{\overline{q_{j}} \prime}{\sum_{j=1}^{n} \overline{q_{j}} \prime}
$$


Step 10. In order to determine the final weights of criteria, it is first necessary to perform the defuzzification of the fuzzy values $\overline{w_{j}}$ and $\overline{w_{j}}$ '

$$
\bar{w}_{j}^{\prime \prime}=\frac{1}{2}\left(w_{j}+w_{j}\right)
$$

Step 11. Checking the results obtained by applying Spearman and Pearson correlation coefficients [51,54].

\section{Assessment of Conditions for the Implementation of Barcode Technology in the Warehouse System Using an Integrated SWOT-Fuzzy PIPRECIA Model}

The company in which the research has been conducted represents a complex logistics system where a constant improvement of logistics activities is necessary in order to increase its efficiency. The company is spread over about a million square meters and is engaged in manufacturing of brown paper. Its success achieved despite some subsystems that are not fully rationalized is confirmed by the fact that it belongs to a group of largest exporters in Bosnia and Herzegovina. A current system in the company is a decentralized system where every manufacturing facility has its own warehouse. So far, a number of studies have been conducted in this company [54-58]. Most of these warehouses have already been equipped with barcode technology. In addition, the warehouse that is of utmost importance for the overall company's operations is a warehouse called "WU Warehouse", which currently operates mainly on a "manual" basis. Therefore, SWOT matrix with a total of 27 elements was formed in this paper and integrated with the fuzzy PIPRECIA method for assessing the conditions, that is, possibilities, of implementing barcode technology into this warehouse.

The "WU Warehouse" has a function of providing support to the maintenance sector, the manufacturing sector as well as the sales sector. This makes it extremely important part of the company. The "WU Warehouse includes: Central weighing scale, Reception Warehouse, the Warehouse of raw material and chemicals, the Warehouse of technical material and the Warehouse of spare parts. In the "WU Warehouse", the purpose of the process is to control input, output and reception of materials/raw materials and finished products by suppliers and freight vehicles and to store them into pre-defined warehouse premises within the company. This paper will focus on the Warehouse of technical material and the Reception Warehouse and the possibility of introducing barcode technology into these warehouses. The two warehouses mentioned in the first phase will be a pilot project onto which an implementation test of barcode technology will be performed. Their practice will serve to identify all positive and negative characteristics introducing barcode technology and in further work, it will be tried to eliminate all the errors in the new system of work.

\subsection{Description of the Reception and Dispatch Process from the "WU Warehouse"}

The work principle of "Work unit-Warehouse" is based on strictly defined steps that all employees of the work unit are obliged to adhere to. The first step in this process includes the arrival of vehicles that supply materials/raw materials and control of vehicle weight when entering the company. The weighing of vehicles is performed by a weighing scale operator. After weighing, a weighing scale operator issues a weighing card to a driver, so the vehicle moves further towards the Reception Warehouse, where the reception warehouse keeper receives accompanying documentation, as follows: invoice, delivery note, $\mathrm{CMR}$, attestation and so forth. Then the reception warehouse keeper checks the received materials and raw materials. After the receipt and control, the reception warehouse keeper informs the "WU Logistics 1" and arranges the unloading of raw materials into warehouses, depending on the type of raw material. After unloading and storing the raw materials, the reception warehouse keeper prepares internal documents for the receipt of goods and after that, certain documentation is submitted to the warehouse keeper and the user of raw materials and the rest to liquidators. In addition, the reception warehouse keeper initiates the process throughout the "WU Logistics 1" and warehouse keepers, organizing unloading into existing warehouses depending on the type of 
material delivered. After unloading, the reception warehouse keeper and warehouse keepers inform the submitter of the order and check the correctness of the materials delivered. Once the reception warehouse keeper receives the material in the system, certain documentation is submitted to the warehouse keeper, the submitter of the order and liquidators. After that, materials are stored into existing warehouses within the company at pre-determined positions or handed over to the users directly to their facilities. The warehouse keeper organizes the storage of the material by assigning a suspension card with the exact name, ID number (article number) when placing the item on the shelves. Additional control of material weight, quantity and visual appearance is performed when storing the material. When issuing materials/raw materials, users are obliged to provide the warehouse keeper with accompanying documentation for taking the goods out from the warehouse. After taking a requisition form, the warehouse keeper issues the goods and removes it from the inventory record of the warehouse forming an "Output material" document.

\subsubsection{Processes in the Reception Warehouse}

In the reception warehouse, the reception warehouse keeper receives assignments from his manager. When goods arrive, the warehouse keeper receives the goods on the basis of suppliers' invoices, waybills, transportation providers, forwarders' documents, postal orders, orders and contracts. In case that the goods received do not correspond to the characteristics stated in the accompanying documentation in terms of type, quantity or damage caused by transportation, the warehouse keeper is obliged to inform the supplier and the superior about it. After receiving the raw materials/materials, they are delivered to certain sectors or warehouses, depending on where they are to be stored. Employees in the reception warehouse also make a receipt, that is, by its creation, raw material is received into the warehouse. In the warehouse, the receipt is always accompanied with certain documentation, such as: transportation notes, delivery notes or other records. Consignments and receipts must be recorded into the book of raw materials and additional material. The consignments, received at the warehouse of raw materials and additional materials, must be delivered on a daily basis to liquidation. Liquidation is a part of the company that controls all of the bookkeeping documentation that has generated and recorded changes in business and which are the subject of bookkeeping records. The warehouse keeper is obliged to comply with all technical and technological standards regarding labour regulations. In case the warehouse keeper fails to comply with the regulations made at the company level, he is obliged to report to the manager for his actions.

\subsubsection{Processes in the Warehouse of Technical Material}

As is the case with the reception warehouse, in the warehouse of technical material, a warehouse keeper also receives the assignments from a manager. The warehouse of technical material receives and delivers goods from the Reception Warehouse, the Warehouse of raw materials and chemicals, the Warehouse of technical materials and the Warehouse of spare parts. Within the Warehouse of technical material, the warehouse keeper participates in reception, planning, management, monitoring, control, storage and keeping raw materials, chemicals, technical materials, spare parts and so forth. The warehouse keeper also receives materials from a reception warehouse keeper. Materials are accompanied with certain supporting documentation. After receiving materials and supporting documentation, the warehouse keeper opens new suspension cards if there is a need for that and if it does not, they store the materials into pre-determined locations. Within the Technical Warehouse, it is required to have warehouse material bookkeeping-Input material, that is, bookkeeping accompanied with a record of current inventory and movement of materials by type, quantity and value. The warehouse keeper in the Warehouse of technical material, together with the chief warehouse keeper, is obliged to monitor the realization of all orders relating to the "WU Warehouse." The warehouse keeper is in charge of forming, monitoring, analysing and managing inventory. The warehouse keeper collects useful information on quality of material and indirectly participates in the improvement of quality in an ordering process (PPE equipment, bearings, cutting and grinding materials, office 
supplies, spare parts, etc.). Regarding technical and technological standards and regulations on labour safety that exist in the company, the warehouse keeper is obliged to comply with them while working at his workplace. For everything regarding his work, the warehouse keeper is required to report to his superior.

\subsection{SWOT Analysis of a Warehouse System}

In order to carry out an analysis of the existing and explore the advantages of the future system (a barcode system), SWOT analysis has been applied on the basis of which the assessment of the conditions of barcode technology implementation is performed. Based on the developed model in this research, it is possible to perform an action plan for the realization of planned activities for the complete introduction of barcode technology to the whole work chain of the "WU Warehouse" (reception, control, processing, storage, inventory and issuing materials/raw materials).

SWOT analysis is a highly efficient tool for understanding and support when making decisions in a variety of situations in a company or organization. SWOT analysis has been given such a name because its basic idea is to enable the organization's developmental behaviour, which ensures maximum utilization of chances and capabilities, finding the ways to minimize weaknesses and threats. In this way, SWOT analysis enables the recognition of positive and negative factors and gives the possibility to react to them on time. More precisely, SWOT analysis helps to determine where the organization is in the present, what are its main advantages and weaknesses and what are its chances and obstacles in order to reach the planned goals in the future. Table 3 shows the dimensions and elements for each of the dimensions of SWOT analysis in the observed storage system at Natron-Hayat company.

Table 3. SWOT analysis for implementing barcode technology into the warehouse at Natron-Hayat.

\begin{tabular}{|c|c|}
\hline STRENGTHS & WEAKNESSES \\
\hline Human resources in the warehouse system & Difficulties in inventory control \\
\hline $\begin{array}{l}\text { A linked work system among the Weighing Scale, Reception } \\
\text { Warehouse and the Warehouse of technical material }\end{array}$ & Difficulties in supplementing warehouse inventory \\
\hline Good organization of the work unit & \multirow{2}{*}{$\begin{array}{l}\text { The problem with the way of confirming the material issued } \\
\text { The excessive period between taking materials out and their } \\
\text { confirmation }\end{array}$} \\
\hline Good relationship between warehouse keepers and users & \\
\hline $\begin{array}{l}\text { All items are clearly marked and sorted throughout the } \\
\text { warehouse (suspension cards) }\end{array}$ & Keeping records of debts \\
\hline \multirow[b]{2}{*}{ Access to the main road } & $\begin{array}{l}\text { Wasting the warehouse keepers' time on material confirmation } \\
\text { Consumption of office supplies when performing all warehouse }\end{array}$ \\
\hline & $\begin{array}{c}\text { Warehouse keepers' errors when recording materials } \\
\text { Current IT system of work }\end{array}$ \\
\hline OPPORTUNITIES & THREATS \\
\hline Automatic inventory control & $\begin{array}{c}\text { Employer's lack of understanding of the importance to } \\
\text { introduce a barcode }\end{array}$ \\
\hline Faster supplementing of monthly warehouse inventory & $\begin{array}{c}\text { Users' lack of understanding of the importance to keep the } \\
\text { warehouse using a barcode system }\end{array}$ \\
\hline Faster confirmation of goods by users & $\begin{array}{c}\text { The warehouse keepers' lack of understanding of the importance } \\
\text { to introduce a barcode system into the warehouse }\end{array}$ \\
\hline Eliminating faults when typing a requisition form & Provision of financial resources \\
\hline $\begin{array}{l}\text { Eliminating the waste time of warehouse keepers to keep } \\
\text { records of debts }\end{array}$ & \\
\hline Modernization of WU Warehouse operation & \\
\hline Confidence between warehouse keepers and users & \\
\hline
\end{tabular}

\subsubsection{Strengths}

Within the Warehouse of technical material and the Reception Warehouse, five warehouse keepers are employed; two warehouse keepers at the Reception Warehouse and three warehouse keepers at the Warehouse of Technical Material. All employees in these warehouses have been educated and trained to perform all warehouse operations, such as: reception, control, sorting, storage, control, supplementing and dispatch of goods. As a part of regular business operations within the "WU Warehouse", there is a linkage of work process between the weighing scale and the Reception Warehouse from where the 
distribution of goods to final users is performed. This system of work has been performed for a number of years without major problems. Regarding the organization of work within the work unit, it implies that warehouse keepers operate following a certain and predefined work system. They use an existing ERP information system. The ERP system is an information system in the company that covers a database of manufacturing (it is precisely known how much it has been manufactured at the moment in order for those in the sales sector to know how much they can sell, and, in the warehouse, how much they can store), sales, procurement (in order that the procurement system has information on how much raw material/material is currently in the warehouse), human resources (data on employees), warehouses (warehouse keepers working as a support to production, raw material storage, support for production and storage of finished goods). As a part of the work unit as well as the entire company, ISO 9001 2015, with clear work descriptions, work instructions, work processes and forms for creating accompanying documentation, has been introduced. The advantage is that everyone is familiar with this but introducing a barcode technology system it would be easier to run the warehouse, as all would be automatically performed and the whole process would be far faster. Good relationship between warehouse keepers and users implies cooperation and teamwork. In order to complete work in the best way, a good relationship between warehouse keepers and users is required, which is also achieved by communication between them. Users are essentially employees on other jobs, who take necessary material from the Warehouse of technical material, while there are no external users. As a result of that and numerous successful activities, there is a trust between warehouse keepers and users, which significantly facilitates the warehousing process itself as well as the opportunity to introduce new innovations in the work. For better organization of work, the Warehouse of technical material is due to a large number of items and their variety divided in the system throughout six sub-warehouses. All the items are arranged in clearly visible places, marked by columns and rows, more precisely, the positioning of larger part of items within the warehouse has been completed. Each item has its own suspension card with the name, number and type of item. The proper layout of material by certain types ensures easier warehousing because when warehouse keepers search for a particular item, they know where the item is located. Consequently, this has an advantage regarding serving speed, since the user who is waiting for a particular item does not have to wait too long. Work conditions in the warehouse are very favourable. The warehouse is neat and clean. At work, it is very important to have cleanliness and neatness. Favourable conditions at work lead to moral satisfaction of employed warehouse keepers, which therefore leads to their better performance in the warehouse. The Reception Warehouse as well as the Warehouse of technical material have access to the main road, which enables them uninterrupted internal transportation, that is, the reception and distribution of materials to the final users within the company. The fact that materials and raw materials arrive uninterruptedly to a certain place is an advantage offered by the current system.

\subsubsection{Weaknesses}

Due to higher frequency and flow of goods throughout warehouses, warehouse keepers and users do not have an ability to display directly the remaining inventory of certain materials. This refers to a physical display of inventory that cannot be identified with $100 \%$ confidence regarding the record of current inventory in the ERP system. Specifically, the current inventory in the ERP system and the physical current inventory do not match because of delay in confirmation of previously issued material. This example can be explained through a situation when a user wants to take a certain item through the system. The system provides him with information that the amount of the material is, for example, two pieces, whereas another user has taken the same item in the meantime but because of delay in confirmation, the system will still show that the inventory of the material is two pieces. Supplementing inventory to the Warehouse of technical material is performed at a monthly level. Checking the warehouse current inventory is an indispensable process because it is necessary to monitor and control the minimum inventory of materials. When supplementing the inventory, prior to the formation of an order, the warehouse keeper checks the materials through the system. The previous example 
explains the problem with differences between the current inventory in the system and the physical current inventory of material, which will also be reflected to the inventory control when supplementing material into the warehouse. This can be explained by the example when a warehouse keeper, in order to save time creating orders, uses the ERP system. In this case, the warehouse keeper must make extra efforts and additional pressure on the users to accelerate the confirmation of the material after which he performs additional control over the validity of the material issued and then performs bookkeeping of all requisition forms. After that, the warehouse keeper will have a complete display of inventory and he can begin to create orders to supplement the minimum inventory of materials. By introducing a barcode system, this problem would be solved, and time would not be wasted on such things but a real amount of inventory would be provided at any moment. Because of the variety of assortments and similarities in item names, there are mistakes caused by users who exclude materials from the warehouse and subsequently make confirmation through the system. Because of imprecision when typing requisition, there is a mistake with similar product names. If the item "Bearing 6204" is used for example, there are five types with similar names (Bearing 6204, Bearing $6204 \mathrm{ZZ}$, Bearing $6204 \mathrm{ZZ/C3}$, Bearing 6204 2RSH, Bearing 6204 NR). Thus, there could be a problem if the user takes one bearing and confirms a completely different one. The problem is that the user has taken one bearing and the other one is registered for the current inventory in the system. The inventory decreases for one item and increases for another one, which further creates a problem in the warehouse keeper's work. In some situations, the user does not immediately confirm materials. This is due to the oversized workload of both the production and maintenance of the plant, so after the material has been taken, the material is subsequently confirmed by users. When taking materials from the warehouse, the user receives the requested material from the warehouse keeper with a note that provides required information for confirmation (quantity, identification number, number of warehouses ... ). This requires additional delay and a waste of time, since the user takes the material and later, when he has some free time, he makes material confirmation in his office. With this warehouse system, the system cannot provide full information to the users about the exact current amount of certain materials, so the users call the warehouse in order to receive the precise information on inventory, which requires additional warehouse work and additional time loss. Regarding keeping records of debt, it can be linked to the previous example. At present, keeping records of debts in a notebook is performed in an unusual way. When issuing materials, the warehouse keeper writes the number of the material issued on behalf of the name of users and thus records the debts. This unpopular work mode occurs due to material confirmation delay by users. The previous work mode in the Warehouse of technical material leads to wasting the warehouse keeper's time to confirm the material taken from the warehouse. In case that the user, who has taken the material from the warehouse, does not confirm this material over a certain period, the warehouse keeper must send an e-mail to remind them that the goods should be confirmed because the system lacks the material. By this system, the warehouse keeper wastes a lot of time that could be used more efficiently. Consuming office supplies while performing all warehouse activities is another weakness of the current system. When issuing materials from the warehouse, the warehouse keeper must print all necessary documentation accompanying with the material, such as: Requisition and Output document. Thus, the warehouse keeper wastes his time and creates costs for paper, printer, electricity and so forth. By introducing bar technology, these activities would be left out. In their work, warehouse keepers encounter the problem that the user did not type a requisition form with the required material. In these situations, the warehouse keeper has problems with the lack of information, so there are situations when the wrong material is issued. This can be associated with the example of Bearing 6204, when a user requires one type of bearing and actually needs another one. Regarding the current IT system within the warehouse, there are six sub-warehouses with different types and subgroups of items. The items are also marked physically in the warehouse, as well as in the system, so each sub-warehouse has certain types of items. It is impossible to issue some material from the warehouse if it does not belong to a specific sub-warehouse. The reason for this is that it cannot be confirmed in the system. Stored goods should be protected from possible malfunction, corrosion, 
breakage and other harmful impacts. This is achieved by proper handling, control and storage of the goods. The ERP system is used as a part of warehousing, which makes it easier for the warehouse keeper to work. However, the system offers an option of upgrading, which would facilitate business and eliminate the shortcomings that currently exist.

\subsubsection{Opportunities}

The recent inventory management has been a major problem in the warehouse; there is no real inventory record in the warehouse at any moment. By introducing a barcode system, this problem, so far created by an old system, is eliminated. The reason for this is that the barcode system can automatically identify the current amount of inventory, so there is no difference between the physical amount of inventory and the current amount in the system. A monthly inventory supplement in the Warehouse of technical material is a big problem, because when it comes to the supplement, it is necessary to look at the current inventory in the system and the current inventory in the warehouse. The barcode system identifies the current inventory and no additional control and inventory tracking are required. It is not necessary to check all items on stock. It is sufficient just to review the current inventory in the system and make a monthly inventory supplement in the warehouse. Moreover, when inventory is scanned in the warehouse, the barcode reader will immediately display an accurate amount of material in the system. The barcode data reading is very short, so an inventory worker can register a large amount of material in a short period. The barcode system is a faster way than the currently used system because a barcode system works on the principle of automatic code reading and automatic requisition creation by a warehouse keeper for the material being issued. This system accelerates the process of work and does not waste any time on material confirmation. This also saves office supplies, toners and so forth, which was previously needed to confirm the material being issued. By introducing a barcode technology system, errors in typing a requisition form are eliminated because a warehouse keeper issues a requisition form immediately with the material issued. However, in the current system, the user takes the material out of the warehouse and later, when he has some free time, he types a requisition form in his office. When typing a requisition form, it is possible to make a mistake regarding the name or number of materials. A barcode system completely eliminates errors because the reader automatically reads the code and cannot make any mistake. By introducing a barcode system, debt records and material confirmation by users are eliminated and there are no additional notes in a notebook. A barcode system automatically reads the code when the material is issued and the current amount of inventory in the system is the same as the current amount in the warehouse. The work system currently used in the "WU Warehouse" provides an ability to progress and upgrade. By introducing a barcode system, we modernize the warehouse and make the work easier. The material taken is automatically confirmed and we have the real amount of inventory in the system at any moment. The introduction of barcode system also creates trust between a warehouse keeper and users. Recording goods issued from the warehouse and typing a requisition form by users are no longer necessary because barcode technology is perfuming the job automatically and at the same time when the material is being issued.

\subsubsection{Threats}

When introducing a barcode system, difficulties regarding the employer may arise. His lack of understanding can be for a variety of reasons. Furthermore, the reason for not understanding the importance of barcode system can be users who have adopted the habit of using the existing business system and for who each change is a certain threat and fear in their work. Another threat for the non-realization of barcode system is by warehouse keepers, who have acquired the habit of working on the existing business system and for whom every change is a particular threat and fear in their work. The cause of non-realization may also be financial resources. For the introduction of this technology, it is necessary to allocate certain financial resources required for equipment purchase, 
warehouse workers' training, barcode printing, installing additional software and so forth. These financial resources can be a problem and could stop the realization of the whole idea.

\subsection{Assessment of Conditions for Implementing Barcode Technology by Applying a Fuzzy PIPRECIA Method}

The first step is to form a set of 27 elements and their weights need to be determined by applying a new fuzzy PIPRECIA method. Criteria are sorted as in the SWOT matrix, not taking into account their significance. In addition, in this step, a team of three decision-makers representing the staff employed in the company's warehouse system was formed. In the second step, each decision-maker individually evaluates the criteria, which represents the determination of four basic dimensions of SWOT analysis.

\subsubsection{Assessment of the Main Dimensions of SWOT Matrix}

Tables 4 and 5 shows the assessment of the main dimensions of SWOT matrix for the fuzzy PIPRECIA and the Inverse fuzzy PIPRECIA by three decision-makers and a geometric mean (GM), which value is used to perform further calculation.

Table 4. Assessment of the main dimensions of SWOT matrix by three DMs for the fuzzy PIPRECIA method.

\begin{tabular}{|c|c|c|c|c|c|c|c|c|c|c|}
\hline PIPR. & C1 & & $\mathrm{C} 2$ & & & C3 & & & $\mathrm{C} 4$ & \\
\hline DM1 & & 1.200 & 1.300 & 1.350 & 0.222 & 0.250 & 0.286 & 0.222 & 0.250 & 0.286 \\
\hline DM2 & & 1.200 & 1.300 & 1.350 & 0.222 & 0.250 & 0.286 & 0.222 & 0.250 & 0.286 \\
\hline DM3 & & 1.200 & 1.300 & 1.350 & 0.222 & 0.250 & 0.286 & 0.222 & 0.250 & 0.286 \\
\hline GM & & 1.200 & 1.300 & 1.350 & 0.222 & 0.250 & 0.286 & 0.222 & 0.250 & 0.286 \\
\hline
\end{tabular}

Table 5. Assessment of the main dimensions of SWOT matrix by three DMs for the Inverse fuzzy PIPRECIA method.

\begin{tabular}{cccccccccc}
\hline PIPR-I & C4 & \multicolumn{3}{c}{ C3 } & \multicolumn{3}{c}{ C2 } & \multicolumn{3}{c}{ C1 } \\
\hline DM1 & 1.300 & 1.450 & 1.500 & 1.400 & 1.600 & 1.650 & 0.400 & 0.500 & 0.667 \\
DM2 & 1.200 & 1.300 & 1.350 & 1.400 & 1.600 & 1.650 & 0.400 & 0.500 & 0.667 \\
DM3 & 1.400 & 1.600 & 1.650 & 1.400 & 1.600 & 1.650 & 0.333 & 0.400 & 0.500 \\
GM & 1.297 & 1.445 & 1.495 & 1.400 & 1.600 & 1.650 & 0.376 & 0.464 & 0.606 \\
\hline
\end{tabular}

Based on the assessment of criteria and a geometric mean (GM), Equation (7), a matrix sj is formed. Applying Equation (8), those values are subtracted from the number two. Respecting the rules of operations on fuzzy numbers, the matrix $k j$ is obtained in the following way:

According to Equation (8), the value $\overline{k_{1}}=(1.000,1.000,1.000)$

$\overline{k_{2}}=(2-1.350,2-1.300,2-1.200)=(0.650,0.700,0.800)$

$\overline{k_{3}}=(2-0.286,2-0.250,2-0.222)=(1.714,1.750,1.778)$

$\overline{k_{4}}=(2-0.286,2-0.250,2-0.222)=(1.714,1.750,1.778)$

According to Equation (9), the values of $q j$ are obtained in the following way:

$\overline{q_{1}}=(1.000,1.000,1.000)$

$\overline{q_{2}}=\left(\frac{1.000}{0.800}, \frac{1.000}{0.700}, \frac{1.000}{0.650}\right)=(1.250,1.429,1.538)$

$\overline{q_{3}}=\left(\frac{1.250}{1.778}, \frac{1.429}{1.750}, \frac{1.538}{1.714}\right)=(0.703,0.816,0.897)$

$\overline{q_{4}}=\left(\frac{0.703}{1.778}, \frac{0.816}{1.750}, \frac{0.897}{1.714}\right)=(0.396,0.466,0.524)$

Applying equation (10), the relative weights are calculated as follows:

$\overline{w_{1}}=\left(\frac{1.000}{3.349}, \frac{1.000}{3.711}, \frac{1.000}{3.959}\right)=(0.253,0.269,0.299)$

$\overline{w_{2}}=\left(\frac{1.250}{3.349}, \frac{1.429}{3.711}, \frac{1.538}{3.959}\right)=(0.316,0.385,0.459)$

$\overline{w_{3}}=\left(\frac{0.703}{3.349}, \frac{0.816}{3.711}, \frac{0.897}{3.959}\right)=(0.178,0.220,0.268)$ 
$\overline{w_{4}}=\left(\frac{0.396}{3.349}, \frac{0.466}{3.711}, \frac{0.524}{3.959}\right)=(0.100,0.126,0.156)$

Table 6 shows complete previous calculation and the last column shows the defuzzified values of relative weights of criteria.

Table 6. Calculation and results of the application of fuzzy PIPRECIA for the main dimensions of SWOT matrix.

\begin{tabular}{ccccccccccccccc}
\hline PIPRECIA & & $\mathbf{s j}$ & \multicolumn{3}{c}{$\mathbf{k j}$} & \multicolumn{3}{c}{$\mathbf{q j}$} & & $\mathbf{w j}$ & & DF \\
\hline C1 & & & & 1.000 & 1.000 & 1.000 & 1.000 & 1.000 & 1.000 & 0.253 & 0.269 & 0.299 & 0.271 \\
C2 & 1.200 & 1.300 & 1.350 & 0.650 & 0.700 & 0.800 & 1.250 & 1.429 & 1.538 & 0.316 & 0.385 & 0.459 & 0.386 \\
C3 & 0.222 & 0.250 & 0.286 & 1.714 & 1.750 & 1.778 & 0.703 & 0.816 & 0.897 & 0.178 & 0.220 & 0.268 & 0.221 \\
C4 & 0.222 & 0.250 & 0.286 & 1.714 & 1.750 & 1.778 & 0.396 & 0.466 & 0.524 & 0.100 & 0.126 & 0.156 & 0.126 \\
\hline SUM & & & & & & 3.349 & 3.711 & 3.959 & & & & \\
\hline
\end{tabular}

In order to determine the final weights of criteria, it is necessary to apply Equations (11)-(15), that is, the methodology of inverse fuzzy PIPRECIA method. Based on the assessment carried out by decision-makers and applying a geometric mean, a matrix $s j^{\prime}$ is obtained.

$$
\begin{aligned}
& \overline{s_{1}^{\prime}}=(0.376,0.464,0.606) \\
& \overline{s_{2}^{\prime}}=(1.400,1.600,1.650) \\
& \overline{s_{3}{ }^{\prime}}=(1.297,1.445,1.495)
\end{aligned}
$$

Applying Equation (12), the following values are obtained:

$\overline{k_{4}{ }^{\prime}}=(1.000,1.000,1.000)$

$\overline{k_{3} \prime}=(2-1.495,2-1.445,2-1.297)=(0.505,0.555,0.703)$

$\overline{k_{2} \prime}=(2-1.650,2-1.600,2-1.400)=(0.350,0.400,0.600)$

$\overline{k_{1} \prime}=(2-0.606,2-0.464,2-0.376)=(1.394,1.536,1.624)$

Applying Equation (13), the following values are obtained:

$$
\begin{aligned}
& \overline{q_{4}^{\prime}}=(1.000,1.000,1.000) \\
& \overline{q_{3}^{\prime}}=\left(\frac{1.000}{0.703}, \frac{1.000}{0.555}, \frac{1.000}{0.505}\right)=(1.423,1.801,1.980) \\
& \overline{q_{2}^{\prime}}=\left(\frac{1.423}{0.600}, \frac{1.801}{0.400}, \frac{1.980}{0.350}\right)=(2.372,4.503,5.658) \\
& \overline{q_{1}^{\prime}}=\left(\frac{2.372}{1.624}, \frac{4.503}{1.536}, \frac{5.658}{1.394}\right)=(1.461,2.932,4.058)
\end{aligned}
$$

\begin{tabular}{|c|c|c|c|c|c|c|c|c|c|c|c|c|c|}
\hline PIPRECIA-I & \multicolumn{3}{|c|}{ sj' } & \multicolumn{3}{|c|}{$\mathbf{k j}^{\prime}$} & \multicolumn{3}{|c|}{$q j^{\prime}$} & \multicolumn{3}{|c|}{$w j^{\prime}$} & DF \\
\hline $\mathrm{C} 1$ & 0.376 & 0.464 & 0.606 & 1.394 & 1.536 & 1.624 & 1.461 & 2.932 & 4.058 & 0.115 & 0.286 & 0.649 & 0.318 \\
\hline $\mathrm{C} 2$ & 1.400 & 1.600 & 1.650 & 0.350 & 0.400 & 0.600 & 2.372 & 4.503 & 5.658 & 0.187 & 0.440 & 0.904 & 0.475 \\
\hline $\mathrm{C} 3$ & 1.297 & 1.445 & 1.495 & 0.505 & 0.555 & 0.703 & 1.423 & 1.801 & 1.980 & 0.112 & 0.176 & 0.316 & 0.189 \\
\hline C4 & & & & 1.000 & 1.000 & 1.000 & 1.000 & 1.000 & 1.000 & 0.079 & 0.098 & 0.160 & 0.105 \\
\hline & & & & & & & 6.257 & 10.236 & 12.695 & & & & \\
\hline
\end{tabular}

Then it is required to apply Equation (14) to obtain relative weights for the fuzzy Inverse PIPRECIA method.

$$
\begin{aligned}
& \overline{w_{4}} \prime=\left(\frac{1.000}{12.695}, \frac{1.000}{10.236}, \frac{1.000}{6.257}\right)=(0.079,0.098,0.160) \\
& \overline{w_{3}} \prime=\left(\frac{1.423}{12.695}, \frac{1.801}{10.236}, \frac{1.980}{6.257}\right)=(0.112,0.176,0.316) \\
& \overline{w_{2}} \prime=\left(\frac{2.372}{12.695}, \frac{4.503}{10.236}, \frac{5.658}{6.257}\right)=(0.187,0.440,0.904) \\
& \overline{w_{1} \prime}=\left(\frac{1.461}{12.695}, \frac{2.932}{10.236}, \frac{4.058}{6.257}\right)=(0.115,0.286,0.649)
\end{aligned}
$$

The results of the inverse fuzzy PIPRECIA methods are presented in Table 7.

Table 7. Calculation and results applying the Inverse fuzzy PIPRECIA for the main dimensions of SWOT matrix.

Applying Equation (15), the final weights of criteria are obtained. Before applying this equation, it is necessary to perform the defuzzification of the values of criteria obtained using Equations (7)-(15). 


$$
\begin{aligned}
& w_{1}^{\prime \prime}=\frac{0.271+0.318}{2}=0.295 \\
& w_{2}^{\prime \prime}=\frac{0.386+0.475}{2}=0.430 \\
& w_{3}^{\prime \prime}=\frac{0.221+0.189}{2}=0.205 \\
& w_{4}^{\prime \prime}=\frac{0.126+0.105}{2}=0.116
\end{aligned}
$$

\subsubsection{Assessment of the Elements of Strength Dimension}

The calculation of elements of all SWOT matrix dimensions was performed in the same way. Tables 8-15 show calculations and results for all elements of SWOT matrix.

The weights of strength dimension elements are as follows:

$$
w_{1}^{\prime \prime}=0.158, \quad w_{2}^{\prime \prime}=0.181, \quad w_{3}^{\prime \prime}=0.246, \quad w_{4}^{\prime \prime}=0.146, \quad w_{5}^{\prime \prime}=0.120, \quad w_{6}^{\prime \prime}=0.100, \quad w_{7}^{\prime \prime}=0.093
$$

\subsubsection{Assessment of Weakness Dimension Elements}

The weights of weakness dimension elements are as follows:

$$
w_{1}^{\prime \prime}=0.112, w_{2}^{\prime \prime}=0.112, w_{3}^{\prime \prime}=0.170, w_{4}^{\prime \prime}=0.171, w_{5}^{\prime \prime}=0.148, w_{6}^{\prime \prime}=0.102, w_{7}^{\prime \prime}=0.089, w_{8}^{\prime \prime}=0.103, w_{9}^{\prime \prime}=0.076
$$

\subsubsection{Assessment of Opportunity Dimension Elements}

The weights of opportunity dimension elements are as follows:

$$
w_{1}^{\prime \prime}=0.165, \quad w_{2}^{\prime \prime}=0.176, \quad w_{3}^{\prime \prime}=0.263, \quad w_{4}^{\prime \prime}=0.263, \quad w_{5}^{\prime \prime}=0.099, \quad w_{6}^{\prime \prime}=0.084, \quad w_{7}^{\prime \prime}=0.096
$$

\subsubsection{Assessment of Threat Dimension Elements}

The weights of threat dimension elements are as follows:

$$
w_{1}^{\prime \prime}=0.285, \quad w_{2}^{\prime \prime}=0.183, \quad w_{3}^{\prime \prime}=0.205, \quad w_{4}^{\prime \prime}=0.338
$$


Table 8. Assessment of strength dimension elements by three DMs for the fuzzy PIPRECIA and Inverse fuzzy PIPRECIA method.

\begin{tabular}{|c|c|c|c|c|c|c|c|c|c|c|c|c|c|c|c|c|c|c|c|}
\hline PIPR. & C1 & & $\mathrm{C} 2$ & & & C3 & & & $\mathrm{C} 4$ & & & C5 & & & C6 & & & C7 & \\
\hline DM1 & & 1.100 & 1.150 & 1.200 & 1.200 & 1.300 & 1.350 & 0.286 & 0.333 & 0.400 & 0.500 & 0.667 & 1.000 & 0.500 & 0.667 & 1.000 & 0.667 & 1.000 & 1.000 \\
\hline DM2 & & 1.000 & 1.000 & 1.050 & 1.200 & 1.300 & 1.350 & 0.333 & 0.400 & 0.500 & 0.500 & 0.667 & 1.000 & 0.500 & 0.667 & 1.000 & 0.500 & 0.667 & 1.000 \\
\hline DM3 & & 1.100 & 1.150 & 1.200 & 1.100 & 1.150 & 1.200 & 0.400 & 0.500 & 0.667 & 0.500 & 0.667 & 1.000 & 0.500 & 0.667 & 1.000 & 0.667 & 1.000 & 1.000 \\
\hline GM & & 1.066 & 1.098 & 1.148 & 1.166 & 1.248 & 1.298 & 0.336 & 0.405 & 0.511 & 0.500 & 0.667 & 1.000 & 0.500 & 0.667 & 1.000 & 0.606 & 0.874 & 1.000 \\
\hline PIPR-I & C7 & & C6 & & & C5 & & & C4 & & & $\mathrm{C} 3$ & & & $\mathrm{C} 2$ & & & $\mathrm{C} 1$ & \\
\hline DM1 & & 1.000 & 1.000 & 1.050 & 1.100 & 1.150 & 1.200 & 1.100 & 1.150 & 1.200 & 1.400 & 1.600 & 1.650 & 0.400 & 0.500 & 0.667 & 0.500 & 0.667 & 1.000 \\
\hline DM2 & & 1.100 & 1.150 & 1.200 & 1.100 & 1.150 & 1.200 & 1.100 & 1.150 & 1.200 & 1.300 & 1.450 & 1.500 & 0.400 & 0.500 & 0.667 & 0.667 & 1.000 & 1.000 \\
\hline DM3 & & 1.000 & 1.000 & 1.050 & 1.100 & 1.150 & 1.200 & 1.100 & 1.150 & 1.200 & 1.200 & 1.300 & 1.350 & 0.500 & 0.667 & 1.000 & 0.500 & 0.667 & 1.000 \\
\hline GM & & 1.032 & 1.048 & 1.098 & 1.100 & 1.150 & 1.200 & 1.100 & 1.150 & 1.200 & 1.297 & 1.445 & 1.495 & 0.431 & 0.550 & 0.763 & 0.550 & 0.763 & 1.000 \\
\hline
\end{tabular}

Table 9. Calculation and results of the application of fuzzy PIPRECIA and Inverse fuzzy PIPRECIA for strength dimension elements.

\begin{tabular}{|c|c|c|c|c|c|c|c|c|c|c|c|c|c|}
\hline PIPRECIA & & sj & & & $\mathbf{k j}$ & & & qj & & & wj & & DF \\
\hline $\mathrm{C} 1$ & & & & 1.000 & 1.000 & 1.000 & 1.000 & 1.000 & 1,000 & 0.120 & 0.162 & 0.191 & 0.160 \\
\hline $\mathrm{C} 2$ & 1.066 & 1.098 & 1.148 & 0.852 & 0.902 & 0.934 & 1.070 & 1.108 & 1,173 & 0.128 & 0.179 & 0.224 & 0.178 \\
\hline $\mathrm{C} 3$ & 1.166 & 1.248 & 1.298 & 0.702 & 0.752 & 0.834 & 1.283 & 1.474 & 1,672 & 0.154 & 0.238 & 0.320 & 0.238 \\
\hline $\mathrm{C} 4$ & 0.336 & 0.405 & 0.511 & 1.489 & 1.595 & 1.664 & 0.771 & 0.924 & 1,122 & 0.093 & 0.150 & 0.215 & 0.151 \\
\hline C5 & 0.500 & 0.667 & 1.000 & 1.000 & 1.333 & 1.500 & 0.514 & 0.693 & 1,122 & 0.062 & 0.112 & 0.215 & 0.121 \\
\hline C6 & 0.500 & 0.667 & 1.000 & 1.000 & 1.333 & 1.500 & 0.343 & 0.520 & 1,122 & 0.041 & 0.084 & 0.215 & 0.099 \\
\hline C7 & 0.606 & 0.874 & 1.000 & 1.000 & 1.126 & 1.394 & 0.246 & 0.461 & 1,122 & 0.029 & 0.075 & 0.215 & 0.090 \\
\hline SUM & & & & & & & 5.227 & 6.180 & 8,335 & & & & \\
\hline PIPRECIA-I & & $\mathbf{s j}^{\prime}$ & & & $\mathbf{k j}^{\prime}$ & & & $q j^{\prime}$ & & & $w j^{\prime}$ & & DF \\
\hline $\mathrm{c} 1$ & 0.550 & 0.763 & 1.000 & 1.000 & 1.237 & 1.450 & 0.798 & 1.460 & 2,773 & 0.056 & 0.137 & 0.337 & 0.157 \\
\hline c2 & 0.431 & 0.550 & 0.763 & 1.237 & 1.450 & 1.569 & 1.157 & 1.806 & 2,773 & 0.081 & 0.170 & 0.337 & 0.183 \\
\hline c3 & 1.297 & 1.445 & 1.495 & 0.505 & 0.555 & 0.703 & 1.816 & 2.618 & 3,429 & 0.128 & 0.246 & 0.417 & 0.255 \\
\hline c4 & 1.100 & 1.150 & 1.200 & 0.800 & 0.850 & 0.900 & 1.276 & 1.453 & 1,732 & 0.090 & 0.137 & 0.210 & 0.141 \\
\hline C5 & 1.100 & 1.150 & 1.200 & 0.800 & 0.850 & 0.900 & 1.148 & 1.235 & 1,385 & 0.081 & 0.116 & 0.168 & 0.119 \\
\hline C6 & 1.032 & 1.048 & 1.098 & 0.902 & 0.952 & 0.968 & 1.033 & 1.050 & 1,108 & 0.073 & 0.099 & 0.135 & 0.100 \\
\hline C7 & & & & 1.000 & 1.000 & 1.000 & 1.000 & 1.000 & 1,000 & 0.070 & 0.094 & 0.122 & 0.095 \\
\hline SUM & & & & & & & 8.229 & 10.622 & 14,200 & & & & \\
\hline
\end{tabular}


Table 10. Assessment of weakness dimension elements by three DMs for the fuzzy PIPRECIA and Inverse fuzzy PIPRECIA method.

\begin{tabular}{|c|c|c|c|c|c|c|c|c|c|c|c|c|c|c|c|c|c|c|c|c|c|c|c|c|}
\hline \multirow{2}{*}{$\begin{array}{c}\text { PIPR. } \\
\text { DM1 }\end{array}$} & \multicolumn{3}{|c|}{ C2 } & \multicolumn{3}{|c|}{ C3 } & \multicolumn{3}{|c|}{ C4 } & \multicolumn{3}{|c|}{ C5 } & \multicolumn{3}{|c|}{ C6 } & \multicolumn{3}{|c|}{ C7 } & \multicolumn{3}{|c|}{ C8 } & \multicolumn{3}{|c|}{ C9 } \\
\hline & 1.000 & 1.000 & 1.000 & 1.300 & 1.450 & 1.500 & 1.000 & 1.000 & 1.050 & 0.667 & 1.000 & 1.000 & 0.400 & 0.500 & 0.667 & 0.500 & 0.667 & 1.000 & 1.100 & 1.150 & 1.200 & 0.400 & 0.500 & 0.667 \\
\hline DM2 & 1.000 & 1.000 & 1.050 & 1.200 & 1.300 & 1.350 & 1.000 & 1.000 & 1.000 & 0.500 & 0.667 & 1.000 & 0.400 & 0.500 & 0.667 & 0.500 & 0.667 & 1.000 & 1.100 & 1.150 & 1.200 & 0.500 & 0.667 & 1.000 \\
\hline DM3 & 1.000 & 1.000 & 1.050 & 1.200 & 1.300 & 1.350 & 1.000 & 1.000 & 1.000 & 0.500 & 0.667 & 1.000 & 0.400 & 0.500 & 0.667 & 0.667 & 1.000 & 1.000 & 1.000 & 1.000 & 1.050 & 0.400 & 0.500 & 0.667 \\
\hline GM & 1.000 & 1.000 & 1.033 & 1.232 & 1.348 & 1.398 & 1.000 & 1.000 & 1.016 & 0.550 & 0.763 & 1.000 & 0.400 & 0.500 & 0.667 & 0.550 & 0.763 & 1.000 & 1.066 & 1.098 & 1.148 & 0.431 & 0.550 & 0.763 \\
\hline PIPR-I & \multicolumn{3}{|c|}{$\mathrm{C} 8$} & \multicolumn{3}{|c|}{$\mathrm{C} 7$} & \multicolumn{3}{|c|}{ C6 } & \multicolumn{3}{|c|}{ C5 } & \multicolumn{3}{|c|}{$\mathrm{C} 4$} & \multicolumn{3}{|c|}{ C3 } & \multicolumn{3}{|c|}{$\mathrm{C} 2$} & \multicolumn{3}{|c|}{$\mathrm{C} 1$} \\
\hline DM1 & 1.200 & 1.300 & 1.350 & 0.500 & 0.667 & 1.000 & 1.100 & 1.150 & 1.200 & 1.200 & 1.300 & 1.350 & 1.000 & 1.000 & 1.050 & 0.667 & 1.000 & 1.000 & 0.333 & 0.400 & 0.500 & 1.000 & 1.000 & 1.000 \\
\hline DM2 & 1.100 & 1.150 & 1.200 & 0.500 & 0.667 & 1.000 & 1.100 & 1.150 & 1.200 & 1.200 & 1.300 & 1.350 & 1.100 & 1.150 & 1.200 & 1.000 & 1.000 & 1.000 & 0.400 & 0.500 & 0.667 & 0.667 & 1.000 & 1.000 \\
\hline DM3 & 1.200 & 1.300 & 1.350 & 0.667 & 1.000 & 1.000 & 1.000 & 1.000 & 1.050 & 1.200 & 1.300 & 1.350 & 1.100 & 1.150 & 1.200 & 1.000 & 1.000 & 1.000 & 0.400 & 0.500 & 0.667 & 0.667 & 1.000 & 1.000 \\
\hline GM & 1.166 & 1.248 & 1.298 & 0.550 & 0.763 & 1.000 & 1.066 & 1.098 & 1.148 & 1.200 & 1.300 & 1.350 & 1.066 & 1.098 & 1.148 & 0.874 & 1.000 & 1.000 & 0.376 & 0.464 & 0.606 & 0.763 & 1.000 & 1.000 \\
\hline
\end{tabular}

Table 11. Calculation and results of the application of fuzzy PIPRECIA and Inverse fuzzy PIPRECIA for WEAKNESS dimension elements.

\begin{tabular}{|c|c|c|c|c|c|c|c|c|c|c|c|c|c|}
\hline PIPRECIA & & sj & & & $\mathbf{k j}$ & & & $q j$ & & & wj & & DF \\
\hline $\mathrm{C} 1$ & & & & 1.000 & 1.000 & 1.000 & 1.000 & 1.000 & 1.000 & 0.079 & 0.110 & 0.140 & 0.110 \\
\hline C2 & 1.000 & 1.000 & 1.033 & 0.967 & 1.000 & 1.000 & 1.000 & 1.000 & 1.034 & 0.079 & 0.110 & 0.145 & 0.111 \\
\hline $\mathrm{C} 3$ & 1.232 & 1.348 & 1.398 & 0.602 & 0.652 & 0.768 & 1.303 & 1.534 & 1.719 & 0.103 & 0.169 & 0.241 & 0.170 \\
\hline $\mathrm{C} 4$ & 1.000 & 1.000 & 1.016 & 0.984 & 1.000 & 1.000 & 1.303 & 1.534 & 1.747 & 0.103 & 0.169 & 0.245 & 0.171 \\
\hline C5 & 0.550 & 0.763 & 1.000 & 1.000 & 1.237 & 1.450 & 0.899 & 1.240 & 1.747 & 0.071 & 0.137 & 0.245 & 0.144 \\
\hline C6 & 0.400 & 0.500 & 0.667 & 1.333 & 1.500 & 1.600 & 0.562 & 0.827 & 1.310 & 0.044 & 0.091 & 0.184 & 0.099 \\
\hline $\mathrm{C} 7$ & 0.550 & 0.763 & 1.000 & 1.000 & 1.237 & 1.450 & 0.387 & 0.669 & 1.310 & 0.031 & 0.074 & 0.184 & 0.085 \\
\hline $\mathrm{C} 8$ & 1.066 & 1.098 & 1.148 & 0.852 & 0.902 & 0.934 & 0.415 & 0.741 & 1.538 & 0.033 & 0.082 & 0.216 & 0.096 \\
\hline $\mathrm{C} 9$ & 0.431 & 0.550 & 0.763 & 1.237 & 1.450 & 1.569 & 0.264 & 0.511 & 1.243 & 0.021 & 0.056 & 0.174 & 0.070 \\
\hline SUM & & & & & & & 7.132 & 9.056 & 12.649 & & & & \\
\hline PIPRECIA-I & & $\mathbf{s j}^{\prime}$ & & & $\mathbf{k j}^{\prime}$ & & & $q^{j}{ }^{\prime}$ & & & $w j^{\prime}$ & & DF \\
\hline $\mathrm{C} 1$ & 0.763 & 1.000 & 1.000 & 1.000 & 1.000 & 1.237 & 0.523 & 1.228 & 2.164 & 0.028 & 0.098 & 0.257 & 0.113 \\
\hline $\mathrm{C} 2$ & 0.376 & 0.464 & 0.606 & 1.394 & 1.536 & 1.624 & 0.647 & 1.228 & 2.164 & 0.035 & 0.098 & 0.257 & 0.114 \\
\hline C3 & 0.874 & 1.000 & 1.000 & 1.000 & 1.000 & 1.126 & 1.051 & 1.886 & 3.017 & 0.057 & 0.151 & 0.358 & 0.170 \\
\hline $\mathrm{C} 4$ & 1.066 & 1.098 & 1.148 & 0.852 & 0.902 & 0.934 & 1.184 & 1.886 & 3.017 & 0.064 & 0.151 & 0.358 & 0.171 \\
\hline C5 & 1.200 & 1.300 & 1.350 & 0.650 & 0.700 & 0.800 & 1.106 & 1.702 & 2.572 & 0.060 & 0.136 & 0.305 & 0.151 \\
\hline C6 & 1.066 & 1.098 & 1.148 & 0.852 & 0.902 & 0.934 & 0.885 & 1.191 & 1.672 & 0.048 & 0.095 & 0.198 & 0.104 \\
\hline C7 & 0.550 & 0.763 & 1.000 & 1.000 & 1.237 & 1.450 & 0.827 & 1.075 & 1.425 & 0.045 & 0.086 & 0.169 & 0.093 \\
\hline C8 & 1.166 & 1.248 & 1.298 & 0.702 & 0.752 & 0.834 & 1.199 & 1.330 & 1.425 & 0.065 & 0.106 & 0.169 & 0.110 \\
\hline C9 & & & & 1.000 & 1.000 & 1.000 & 1.000 & 1.000 & 1.000 & 0.054 & 0.080 & 0.119 & 0.082 \\
\hline SUM & & & & & & & 8.421 & 12.527 & 18.455 & & & & \\
\hline
\end{tabular}


Table 12. Assessment of opportunity dimension elements by three DMs for the fuzzy PIPRECIA and Inverse fuzzy PIPRECIA method.

\begin{tabular}{|c|c|c|c|c|c|c|c|c|c|c|c|c|c|c|c|c|c|c|c|}
\hline \multirow{2}{*}{$\begin{array}{c}\text { PIPR. } \\
\text { DM1 }\end{array}$} & \multirow[t]{2}{*}{$\mathrm{C} 1$} & \multicolumn{3}{|c|}{$\mathrm{C} 2$} & \multicolumn{3}{|c|}{$\mathrm{C} 3$} & \multicolumn{3}{|c|}{$\mathrm{C} 4$} & \multicolumn{3}{|c|}{ C5 } & \multicolumn{3}{|c|}{ C6 } & \multicolumn{3}{|c|}{ C7 } \\
\hline & & 1.100 & 1.150 & 1.200 & 1.300 & 1.450 & 1.500 & 1.000 & 1.000 & 1.000 & 0.250 & 0.286 & 0.333 & 0.500 & 0.667 & 1.000 & 1.100 & 1.150 & 1.200 \\
\hline DM2 & & 1.000 & 1.000 & 1.050 & 1.200 & 1.300 & 1.350 & 1.000 & 1.000 & 1.000 & 0.250 & 0.286 & 0.333 & 0.500 & 0.667 & 1.000 & 1.100 & 1.150 & 1.200 \\
\hline DM3 & & 1.000 & 1.000 & 1.050 & 1.200 & 1.300 & 1.350 & 1.000 & 1.000 & 1.000 & 0.250 & 0.286 & 0.333 & 0.667 & 1.000 & 1.000 & 1.000 & 1.000 & 1.050 \\
\hline GM & & 1.032 & 1.048 & 1.098 & 1.232 & 1.348 & 1.398 & 1.000 & 1.000 & 1.000 & 0.250 & 0.286 & 0.333 & 0.550 & 0.763 & 1.000 & 1.066 & 1.098 & 1.148 \\
\hline PIPR-I & C7 & \multicolumn{3}{|c|}{ C6 } & \multicolumn{3}{|c|}{ C5 } & \multicolumn{3}{|c|}{$\mathrm{C} 4$} & \multicolumn{3}{|c|}{$\mathrm{C} 3$} & \multicolumn{3}{|c|}{$\mathrm{C} 2$} & \multicolumn{3}{|c|}{$\mathrm{C} 1$} \\
\hline DM1 & & 0.500 & 0.667 & 1.000 & 1.100 & 1.150 & 1.200 & 1.500 & 1.750 & 1.800 & 1.000 & 1.000 & 1.000 & 0.333 & 0.400 & 0.500 & 0.500 & 0.667 & 1.000 \\
\hline DM2 & & 0.500 & 0.667 & 1.000 & 1.100 & 1.150 & 1.200 & 1.500 & 1.750 & 1.800 & 1.000 & 1.000 & 1.000 & 0.400 & 0.500 & 0.667 & 0.667 & 1.000 & 1.000 \\
\hline DM3 & & 0.667 & 1.000 & 1.000 & 1.000 & 1.000 & 1.050 & 1.500 & 1.750 & 1.800 & 1.000 & 1.000 & 1.000 & 0.400 & 0.500 & 0.667 & 0.667 & 1.000 & 1.000 \\
\hline GM & & 0.550 & 0.763 & 1.000 & 1.066 & 1.098 & 1.148 & 1.500 & 1.750 & 1.800 & 1.000 & 1.000 & 1.000 & 0.376 & 0.464 & 0.606 & 0.606 & 0.874 & 1.000 \\
\hline
\end{tabular}

Table 13. Calculation and results of the application of fuzzy PIPRECIA and Inverse fuzzy PIPRECIA for opportunity dimension elements.

\begin{tabular}{|c|c|c|c|c|c|c|c|c|c|c|c|c|c|}
\hline PIPRECIA & & sj & & & $\mathbf{k j}$ & & & $q j$ & & & wj & & DF \\
\hline $\mathrm{C} 1$ & & & & 1.000 & 1.000 & 1.000 & 1.000 & 1.000 & 1.000 & 0.108 & 0.128 & 0.152 & 0.129 \\
\hline $\mathrm{C} 2$ & 1.032 & 1.048 & 1.098 & 0.902 & 0.952 & 0.968 & 1.033 & 1.050 & 1.108 & 0.111 & 0.134 & 0.168 & 0.136 \\
\hline $\mathrm{C} 3$ & 1.232 & 1.348 & 1.398 & 0.602 & 0.652 & 0.768 & 1.346 & 1.611 & 1.842 & 0.145 & 0.206 & 0.279 & 0.208 \\
\hline $\mathrm{C} 4$ & 1.000 & 1.000 & 1.000 & 1.000 & 1.000 & 1.000 & 1.346 & 1.611 & 1.842 & 0.145 & 0.206 & 0.279 & 0.208 \\
\hline C5 & 0.250 & 0.286 & 0.333 & 1.667 & 1.714 & 1.750 & 0.769 & 0.940 & 1.105 & 0.083 & 0.120 & 0.168 & 0.122 \\
\hline C6 & 0.550 & 0.763 & 1.000 & 1.000 & 1.237 & 1.450 & 0.531 & 0.760 & 1.105 & 0.057 & 0.097 & 0.168 & 0.102 \\
\hline $\mathrm{C} 7$ & 1.066 & 1.098 & 1.148 & 0.852 & 0.902 & 0.934 & 0.568 & 0.842 & 1.297 & 0.061 & 0.108 & 0.197 & 0.115 \\
\hline SUM & & & & & & & 6.594 & 7.814 & 9.299 & & & & \\
\hline PIPRECIA-I & & sj' $^{\prime}$ & & & $\mathbf{k j}^{\prime}$ & & & $q^{j}{ }^{\prime}$ & & & $w j^{\prime}$ & & DF \\
\hline $\mathrm{c} 1$ & 0.606 & 0.874 & 1.000 & 1.000 & 1.126 & 1.394 & 0.652 & 2.072 & 4.208 & 0.028 & 0.145 & 0.606 & 0.202 \\
\hline c2 & 0.376 & 0.464 & 0.606 & 1.394 & 1.536 & 1.624 & 0.909 & 2.334 & 4.208 & 0.039 & 0.163 & 0.606 & 0.216 \\
\hline c3 & 1.000 & 1.000 & 1.000 & 1.000 & 1.000 & 1.000 & 1.476 & 3.584 & 5.867 & 0.063 & 0.251 & 0.845 & 0.319 \\
\hline c4 & 1.500 & 1.750 & 1.800 & 0.200 & 0.250 & 0.500 & 1.476 & 3.584 & 5.867 & 0.063 & 0.251 & 0.845 & 0.319 \\
\hline C5 & 1.066 & 1.098 & 1.148 & 0.852 & 0.902 & 0.934 & 0.738 & 0.896 & 1.173 & 0.032 & 0.063 & 0.169 & 0.075 \\
\hline C6 & 0.550 & 0.763 & 1.000 & 1.000 & 1.237 & 1.450 & 0.690 & 0.809 & 1.000 & 0.030 & 0.057 & 0.144 & 0.067 \\
\hline $\mathrm{C} 7$ & & & & 1.000 & 1.000 & 1.000 & 1.000 & 1.000 & 1.000 & 0.043 & 0.070 & 0.144 & 0.078 \\
\hline SUM & & & & & & & 6.943 & 14.278 & 23.323 & & & & 1.276 \\
\hline
\end{tabular}


Table 14. Assessment of threat dimension elements by three DMs for the fuzzy PIPRECIA and Inverse fuzzy PIPRECIA method.

\begin{tabular}{ccccccccccc}
\hline PIPR. & C1 & \multicolumn{3}{c}{ C2 } & \multicolumn{3}{c}{ C3 } & & C4 \\
\hline DM1 & & 0.286 & 0.333 & 0.400 & 1.100 & 1.150 & 1.200 & 1.300 & 1.450 & 1.500 \\
DM2 & & 0.250 & 0.286 & 0.333 & 1.000 & 1.000 & 1.200 & 1.300 & 1.450 & 1.500 \\
DM3 & & 0.250 & 0.286 & 0.333 & 1.100 & 1.150 & 1.200 & 1.300 & 1.450 & 1.500 \\
GM & & 0.261 & 0.301 & 0.354 & 1.066 & 1.098 & 1.200 & 1.300 & 1.450 & 1.500 \\
\hline PIPR-I & C4 & & C3 & & & C2 & & & C1 & 1.300 \\
\hline DM1 & & 0.400 & 0.500 & 0.667 & 0.667 & 1.000 & 1.000 & 1.200 & 1.350 \\
DM2 & & 0.333 & 0.400 & 0.500 & 0.667 & 1.000 & 1.000 & 1.200 & 1.300 & 1.350 \\
DM3 & & 0.400 & 0.500 & 0.667 & 0.500 & 0.667 & 1.000 & 1.200 & 1.300 & 1.350 \\
GM & 0.376 & 0.464 & 0.606 & 0.606 & 0.874 & 1.000 & 1.200 & 1.300 & 1.350 \\
\hline
\end{tabular}

Table 15. Calculation and results of the application of fuzzy PIPRECIA and Inverse fuzzy PIPRECIA for threat dimension elements

\begin{tabular}{|c|c|c|c|c|c|c|c|c|c|c|c|c|c|}
\hline PIPRECIA & & sj & & & kj & & & $q j$ & & & wj & & DF \\
\hline $\mathrm{C} 1$ & & & & 1.000 & 1.000 & 1,000 & 1.000 & 1.000 & 1.000 & 0.267 & 0.292 & 0.326 & 0.293 \\
\hline C2 & 0.261 & 0.301 & 0.354 & 1.646 & 1.699 & 1.739 & 0.575 & 0.589 & 0.608 & 0.154 & 0.172 & 0.198 & 0.173 \\
\hline C3 & 1.066 & 1.098 & 1.148 & 0.852 & 0.902 & 0.934 & 0.616 & 0.652 & 0.713 & 0.164 & 0.190 & 0.232 & 0.193 \\
\hline C4 & 1.300 & 1.450 & 1.500 & 0.500 & 0.550 & 0.700 & 0.879 & 1.186 & 1.426 & 0.235 & 0.346 & 0.464 & 0.347 \\
\hline SUM & & & & & & & 3.070 & 3.427 & 3.746 & & & & \\
\hline PIPRECIA-I & & $\mathbf{s j}^{\prime}$ & & & $\mathbf{k j}^{\prime}$ & & & $q j^{\prime}$ & & & $\mathbf{w j}$ & & DF \\
\hline c1 & 1.200 & 1.300 & 1.350 & 0.650 & 0.700 & 0.800 & 0.552 & 0.826 & 1.103 & 0.156 & 0.270 & 0.423 & 0277 \\
\hline c2 & 0.606 & 0.874 & 1.000 & 1.000 & 1.126 & 1.394 & 0.442 & 0.578 & 0.717 & 0.125 & 0.189 & 0.275 & 0.193 \\
\hline c3 & 0.376 & 0.464 & 0.606 & 1.394 & 1.536 & 1.624 & 0.616 & 0.651 & 0.717 & 0.174 & 0.213 & 0.275 & 0.217 \\
\hline c4 & & & & 1.000 & 1.000 & 1.000 & 1.000 & 1.000 & 1.000 & 0.283 & 0.327 & 0.383 & 0.329 \\
\hline SUM & & & & & & & 2.610 & 3.055 & 3.538 & & & & \\
\hline
\end{tabular}




\section{Sensitivity Analysis and Discussion of Results}

Sensitivity analysis implies the calculation of Spearman coefficient correlation for the ranks obtained by the fuzzy PIPRECIA method and its inverse fuzzy version. In addition, a Pearson correlation coefficient was calculated for the obtained weights of SWOT matrix elements from both versions of the developed method. In Tables 16-19, ranks and correlation coefficients are shown.

Table 16. Ranks and weight values of main dimensions of SWOT matrix.

\begin{tabular}{cccccccccc}
\hline & Rank & Rank & d & d2 & & I & II & wj & \\
\hline C1 & 2 & 2 & 0 & 0 & C1 & 0.271 & 0.318 & 0.295 & 2 \\
C2 & 1 & 1 & 0 & 0 & C2 & 0.386 & 0.475 & 0.430 & 1 \\
C3 & 3 & 3 & 0 & 0 & C3 & 0.221 & 0.189 & 0.205 & 3 \\
C4 & 4 & 4 & 0 & 0 & C4 & 0.126 & 0.105 & 0.116 & 4 \\
& & & & & & & & SCC & 1.000 \\
& & & & & & & PCC & 0.987 \\
\hline
\end{tabular}

Table 17. Ranks and weight values of strength dimension.

\begin{tabular}{cccccccccc}
\hline & Rank & Rank & $\mathbf{d}$ & $\mathbf{d} 2$ & & I & II & wj & \\
\hline C1 & 3 & 3 & 0 & 0 & C1 & 0.160 & 0.157 & 0.158 & 3 \\
C2 & 2 & 2 & 0 & 0 & C2 & 0.178 & 0.183 & 0.181 & 2 \\
C3 & 1 & 1 & 0 & 0 & C3 & 0.238 & 0.255 & 0.246 & 1 \\
C4 & 4 & 4 & 0 & 0 & C4 & 0.151 & 0.141 & 0.146 & 4 \\
C5 & 5 & 5 & 0 & 0 & C5 & 0.121 & 0.119 & 0.120 & 5 \\
C6 & 6 & 6 & 0 & 0 & C6 & 0.099 & 0.100 & 0.100 & 6 \\
C7 & 7 & 7 & 0 & 0 & C7 & 0.090 & 0.095 & 0.093 & 7 \\
& & & & & & & & SCC & 1.000 \\
& & & & & & & & PCC & 0.992 \\
\hline
\end{tabular}

Table 18. Ranks and weight values of weakness dimension.

\begin{tabular}{cccccccccc}
\hline & Rank & Rank & $\mathbf{d}$ & $\mathbf{d} \mathbf{2}$ & & $\mathbf{I}$ & $\mathbf{I I}$ & $\mathbf{w j}$ & \\
\hline C1 & 5 & 5 & 0 & 0 & C1 & 0.110 & 0.113 & 0.112 & 5 \\
C2 & 4 & 4 & 0 & 0 & C2 & 0.111 & 0.114 & 0.112 & 4 \\
C3 & 2 & 2 & 0 & 0 & C3 & 0.170 & 0.170 & 0.170 & 2 \\
C4 & 1 & 1 & 0 & 0 & C4 & 0.171 & 0.171 & 0.171 & 1 \\
C5 & 3 & 3 & 0 & 0 & C5 & 0.144 & 0.151 & 0.148 & 3 \\
C6 & 6 & 7 & -1 & 1 & C6 & 0.099 & 0.104 & 0.102 & 7 \\
C7 & 8 & 8 & 0 & 0 & C7 & 0.085 & 0.093 & 0.089 & 8 \\
C8 & 7 & 6 & 1 & 1 & C 8 & 0.096 & 0.110 & 0.103 & 6 \\
C9 & 9 & 9 & 0 & 0 & C9 & 0.070 & 0.082 & 0.076 & 9 \\
& & & & & & & & SCC & 0.983 \\
& & & & & & & & PCC & 0.995 \\
\hline
\end{tabular}

Table 19. Ranks and weight values of opportunity dimension.

\begin{tabular}{cccccccccc}
\hline & Rank & Rank & $\mathbf{d}$ & $\mathbf{d} \mathbf{2}$ & & I & II & wj & \\
\hline C1 & 4 & 4 & 0 & 0 & C1 & 0.129 & 0.202 & 0.165 & 4 \\
C2 & 3 & 3 & 0 & 0 & C2 & 0.136 & 0.216 & 0.176 & 3 \\
C3 & 1 & 1 & 0 & 0 & C3 & 0.208 & 0.319 & 0.263 & 1 \\
C4 & 1 & 1 & 0 & 0 & C4 & 0.208 & 0.319 & 0.263 & 1 \\
C5 & 5 & 6 & -1 & 1 & C5 & 0.122 & 0.075 & 0.099 & 5 \\
C6 & 7 & 7 & 0 & 0 & C6 & 0.102 & 0.067 & 0.084 & 7 \\
C7 & 6 & 5 & 1 & 1 & C7 & 0.115 & 0.078 & 0.096 & 6 \\
& & & & & & & & SCC & 0.964 \\
& & & & & & & & PCC & 0.924 \\
\hline
\end{tabular}


As it can be seen in Table 16, the most significant dimension of SWOT analysis is WEAKNESS dimension with a value of 0.430 . The research has identified nine elements of weaknesses that can be significantly eliminated by implementing barcode technology. The least significant dimension is THREATS, which is a positive fact in this research and provides greater probability for the implementation of this technology. Additionally, Table 16 presents the ranks that are identical by applying the fuzzy PIPRECIA and inverse fuzzy PIPRECIA methods, which means that the ranks are in full correlation $(S C C=1.000)$. The high reliability of obtained results is proved by the value of Pearson correlation coefficient $(P C C=0.987)$.

Seven elements have been identified in the STRENGTH dimension, where the third one is the most important, which implies a good organization of the work unit. This element is closely related to the next two most important elements related to a good link between "WU Warehouse" elements and human resources in the warehouse system. It must be emphasized that the company invests in its staff providing support in their education and training. In addition, the company has a large number of young people who are prepared and capable of teamwork and continuous training. The less important elements of this dimension are the relations between warehouse keepers and users and marking of all items. The least important elements are work conditions in the warehouse and access to the main road. The correlation coefficients show full correlation regarding ranks and almost full correlation regarding weight elements.

By SWOT analysis, most elements have been identified in the WEAKNESS dimension. At present, the greatest weakness of the existing system is a long period between the time of the material being taken out and its confirmation and the confirmation of materials that have almost the same value. The previous two elements are closely related to the third biggest weakness associated with the fifth element-keeping records of debts. All of this affects the efficiency of the entire warehouse system and inventory in it, since there are difficulties in controlling inventory and its supplement. All of the above-mentioned elements or weaknesses can be eliminated by implementing barcode technology, which can be seen below in the Opportunity dimension. Regarding rank correlations, it is incomplete $(S C C=0.983)$ because there is a change in the rank of sixth and eighth elements that change their positions by applying fuzzy PIPRECIA and inverse fuzzy PIPRECIA method. Regarding weight correlation, it is higher than the correlation of ranks and it is $P C C=0.995$.

Possibilities, that is, opportunities that can be achieved by introducing barcode technology in a warehouse system are multiple and, of course, closely related to current shortcomings, that is, weaknesses. Seven options are defined in total, from which a faster way of confirmation goods by users and eliminating mistakes when typing a requisition form is most important. By acquiring these opportunities, it is possible to make inventory supplement quicker and make automatic inventory control, which is an important element to be achieved by implementing barcode technology. Correlation coefficients are still very high. Observing the overall research and integration of SWOT and fuzzy PIPRECIA method, the least values of ranks have been achieved in the Opportunity dimension. The fifth and seventh element change their ranking positions, which results in a value of SCC $=0.964$ and a value of $P C C=0.924$.

Four elements have been identified throughout this dimension, of which, in the SWOT analysis, the biggest threat (Table 20) is the provision of financial resources. Although it is a company that is, as noted above, one of the largest exporters in the country, the inability to provide funds for this project is still present. The cause can be justified by the recent reconstruction of manufacturing plants when the company had to stop the manufacturing process for a few months. In addition, the employer's possible lack of understanding of the importance to implement barcode technology is also present, which is one of the reasons for conducting this research and such analysis. The reason for this is that the warehouse of finished products has already been equipped with this technology and it is taken most into account, while other warehouses are considered less important. The correlation of ranks in this dimension is complete and the value of Pearson correlation coefficient is 0.994 . 
Table 20. Ranks and weight values of the treaths dimensions.

\begin{tabular}{cccccccccc}
\hline & Rank & Rank & d & d2 & & I & II & wj & \\
\hline C1 & 2 & 2 & 0 & 0 & C1 & 0.293 & 0.277 & 0.285 & 2 \\
C2 & 4 & 4 & 0 & 0 & C2 & 0.173 & 0.193 & 0.183 & 4 \\
C3 & 3 & 3 & 0 & 0 & C3 & 0.193 & 0.217 & 0.205 & 3 \\
C4 & 1 & 1 & 0 & 0 & C4 & 0.347 & 0.329 & 0.338 & 1 \\
& & & & & & & & SCC & 1.000 \\
& & & & & & & & PCC & 0.994 \\
\hline
\end{tabular}

When a complete sensitivity analysis has been considered, it can be concluded that the results obtained by the developed model are stable and that the ranks within the developed method and values of weight elements tend to correlate fully. One of the reasons for this correlation is the education of human resources in the company about how to apply new fuzzy scales defined in this paper. Table 21 shows complete unified results of SWOT-Fuzzy PIPRECIA method that relate to local and global values of elements for each dimension individually and global ranks of elements.

Table 21. Final results of the developed SWOT-Fuzzy PIPRECIA model.

\begin{tabular}{|c|c|c|c|}
\hline Dimension Elements & Local Value & Global Value & Rank \\
\hline \multicolumn{4}{|c|}{ STRENGTHS } \\
\hline $\mathrm{C} 1$ & 0.158 & 0.047 & 10 \\
\hline $\mathrm{C} 2$ & 0.181 & 0.053 & 7 \\
\hline $\mathrm{C} 3$ & 0.246 & 0.073 & 3 \\
\hline $\mathrm{C} 4$ & 0.146 & 0.043 & 13 \\
\hline $\mathrm{C} 5$ & 0.120 & 0.035 & 17 \\
\hline C6 & 0.100 & 0.029 & 21 \\
\hline $\mathrm{C} 7$ & 0.093 & 0.027 & 22 \\
\hline \multicolumn{4}{|c|}{ WEAKNESSES } \\
\hline $\mathrm{C} 1$ & 0.112 & 0.048 & 9 \\
\hline $\mathrm{C} 2$ & 0.112 & 0.048 & 8 \\
\hline C3 & 0.170 & 0.073 & 2 \\
\hline $\mathrm{C} 4$ & 0.171 & 0.074 & 1 \\
\hline $\mathrm{C} 5$ & 0.148 & 0.064 & 4 \\
\hline C6 & 0.102 & 0.044 & 12 \\
\hline $\mathrm{C} 7$ & 0.089 & 0.038 & 15 \\
\hline $\mathrm{C} 8$ & 0.103 & 0.044 & 11 \\
\hline C9 & 0.076 & 0.033 & 20 \\
\hline \multicolumn{4}{|c|}{ OPPORTUNITIES } \\
\hline $\mathrm{C} 1$ & 0.165 & 0.034 & 18 \\
\hline $\mathrm{C} 2$ & 0.176 & 0.036 & 16 \\
\hline $\mathrm{C} 3$ & 0.263 & 0.054 & 5 \\
\hline $\mathrm{C} 4$ & 0.263 & 0.054 & 5 \\
\hline C5 & 0.099 & 0.020 & 25 \\
\hline C6 & 0.084 & 0.017 & 27 \\
\hline $\mathrm{C} 7$ & 0.096 & 0.020 & 26 \\
\hline \multicolumn{4}{|c|}{ THREATS } \\
\hline $\mathrm{C} 1$ & 0.285 & 0.033 & 19 \\
\hline $\mathrm{C} 2$ & 0.183 & 0.021 & 24 \\
\hline $\mathrm{C} 3$ & 0.205 & 0.024 & 23 \\
\hline $\mathrm{C} 4$ & 0.338 & 0.039 & 14 \\
\hline
\end{tabular}

As already mentioned, the SWOT matrix contains 27 elements, where the weaknesses of the current system represent the most realistic elements, so the implementation of barcode technology is justified. Its introduction creates the conditions for eliminating weaknesses and increasing the 
efficiency of the whole "WU Warehouse." One of the constraints of the formed SWOT analysis is its hierarchical structure. In order to provide more precise global values and ranks of elements, it is necessary that the main criteria or, in this case, dimensions have the same number of elements in the hierarchical structure, which was also noticed in the research [59].

The paper [60] presents a methodological and practical framework for selecting suitable MCDA methods for a particular decision situation. A set of 56 available MCDA methods was analyzed and, based on that, a hierarchical set of methods' characteristics and the rule base were obtained. This study is very useful, but according to our opinion has a lot of space for improvement, because new MCDM method and concepts like rough set are omitted. Fuzzy PIPRECIA methodology can be used in various fields for group decision-making process for determination weights of criteria especially can be useful for assessment by a large number of decision makers. In order to enable the reduction of subjectivity and uncertainty in a decision-making process, a new fuzzy PIPRECIA method has been developed, the advantages of which are presented throughout the paper. More precise and objective expression of uncertainty processes is also possible if one applies Hesitant multiplicative preference relation (HMPR) [61], the hesitant probabilistic multiplicative preference relation (HPMPR) [62], the probabilistic single-valued neutrosophic hesitant fuzzy set (PSVNHFS) [63], hesitant fuzzy set theory [64-66]. Uncertainty and imprecision of data describing the alternatives and criteria influence the subjectivity of assessment [67]. Therefore, in the last few years, there has been a dynamic development of fuzzy MCDM methods, which allow capturing uncertainty and imprecision of input data representing values of alternatives and weights of criteria [68].

\section{Conclusions}

In this paper, a pre-analysis of barcode implementation in a warehouse system of a company for the manufacture of brown paper has been carried out. In order to get as realistic indicators as possible, SWOT matrix was formed with a total of 27 elements, which were assessed. The conducted research has double contribution, both scientific and practical. The greatest contributions from a scientific aspect are the enrichment of multi-criteria decision-making methodology throughout development of new fuzzy criterion scales and new fuzzy PIPRECIA method. New fuzzy scales for criteria comparison adapted to the developed methodology have been defined. In order to enable the reduction of subjectivity and uncertainty in a decision-making process, a new fuzzy PIPRECIA method has been developed, the advantages of which are presented throughout the paper. This method makes it possible to evaluate unsorted criteria, which is very important for group decision-making, especially when the number of decision-makers increases. If the contribution from a practical aspect is observed, it can be emphasized that by assessing the conditions for the application of barcode technology in this part of the company, an adequate basis for increasing the efficiency of logistics operations is achieved. It is a company that has about one thousand employees and covers about one million square meters, including a large volume of exports and a large number of logistics operations and processes. Increasing its efficiency makes it possible to increase efficiency of a complete supply chain involving a large number of users with regard to company's business scope. Future research regarding this work relates to the implementation of barcode technology, both in these warehouse systems and in other ones that are not covered by this technology. In addition, it is possible to develop similar models for criteria evaluation. One of the directions is expansion of PIPRECIA method with rough numbers that help to reduce uncertainty when making decisions and relates to group decision-making.

Author Contributions: Each author has participated and contributed sufficiently to take public responsibility for appropriate portions of the content.

Funding: This study was partially supported by the research project "Integration of Information and Communication Technology for sustainable cities in South Africa" funded by National Research Foundation (NRF), South Africa (Grant Number: 106023, 15-12-2016). The authors would like to acknowledge the NRF, South Africa for the support.

Conflicts of Interest: The authors declare no conflict of interest. 


\section{References}

1. Novičević, M.M.; Harvey, M.; Autry, C.W.; Bond III, E.U. Dual-perspective SWOT: A synthesis of marketing intelligence and planning. Mark. Intell. Plan. 2004, 22, 84-94. [CrossRef]

2. Ananda, J.; Herath, G. A critical review of multi-criteria decision making methods with special reference to forest management and planning. Ecol. Econ. 2009, 68, 2535-2548. [CrossRef]

3. Saaty, T.L. Theory and Applications of the Analytic Network Process: Decision Making with Benefits, Opportunities, Cost, and Risk; RWS Publications: Pittsburgh, PA, USA, 2005.

4. Yalcin, M.; Gul, F.K. A GIS-based multi criteria decision analysis approach for exploring geothermal resources: Akarcay basin (Afyonkarahisar). Geothermics 2017, 67, 18-28. [CrossRef]

5. Malczewski, J.; Rinner, C. Multicriteria Decision Analysis in Geographic Information Science; Springer: New York, NY, USA, 2015.

6. MacCrimmon, K.R. Improving the System Design and Evaluation Process by the Use of Trade-off Information (Memorandum RM-5877-DOT); The Rand Corporation: Santa Monica, CA, USA, 1969.

7. Keeney, R.L.; Raiffa, H. Decisions with Multiple Objectives: Preferences and Value Tradeoffs; Wiley: New York, NY, USA, 1976.

8. Pitz, G.F.; McKillip, J. Decision Analysis for Program Evaluators; SAGE Publications: Beverly Hills, CA, USA, 1984.

9. Malczewski, J. GIS and Multicriteria Decision Analysis; John Wiley \& Sons: New York, NY, USA, 1999.

10. Zhou, P.; Ang, B.W.; Poh, K.L. Decision analysis in energy and environmental modeling: An update. Energy 2006, 31, 2604-2622. [CrossRef]

11. Løken, E. Use of multicriteria decision analysis methods for energy planning problems. Renew. Sustain. Energy Rev. 2007, 11, 1584-1595.

12. Yap, H.Y.; Nixon, J.D. A multi-criteria analysis of options for energy recovery from municipal solid waste in India and the UK. Waste Manag. 2015, 46, 265-277. [CrossRef] [PubMed]

13. Aravossis, K.; Anagnostopoulos, P.; Koungolos, A.; Vliamos, S. A New Methodology Approach for the Technical-Economical Evaluation of Alternative Waste Disposal Methods by Use of Multi Criteria Analysis. In Proceedings of the Seventh International Conference on Environmental Science and Technology, September 2001; pp. 40-51. Available online: http://arvis.simor.ntua.gr/Attachments/Publications/ Conferences/mekrites/7.6.7_A\%20NEW\%20METHODOLOGY\%20APPROACH\%20FOR\%20THE\% 20TECHNICAL\%20ECONOMICAL\%20EVALUATION.pdf (accessed on 1 November 2018).

14. Hsu, P.; Wu, C.; Li, Y. Selection of infectious medical waste disposal firms by using the analytic hierarchy process and sensitivity analysis. Waste Manag. 2008, 28, 1386-1394. [CrossRef] [PubMed]

15. De Feo, G.; De Gisi, S. Using an innovative criteria weighting tool for stakeholders' involvement to rank MSW facility sites with the AHP. Waste Manag. 2010, 30, 2370-2382. [CrossRef] [PubMed]

16. Soltani, A.; Hewage, K.; Reza, B.; Sadiq, R. Multiple stakeholders in multicriteria decision-making in the context of municipal solid waste management: A review. Waste Manag. 20115, 35, 318-328. [CrossRef] [PubMed]

17. Badi, I.; Ballem, M. Supplier selection using the rough BWM-MAIRCA model: A case study in pharmaceutical supplying in Libya. Decis. Mak. Appl. Manag. Eng. 2018, 1, 16-33. [CrossRef]

18. Božanic, D.; Tešic, D.; Milicevic, J. A hybrid fuzzy AHP-MABAC model: Application in the Serbian Army-The selection of the location for deep wading as a technique of crossing the river by tanks. Decis. Mak. Appl. Manag. Eng. 2018, 1, 143-164. [CrossRef]

19. Nixon, J.D.; Dey, P.K.; Ghosh, S.K.; Davies, P.A. Evaluation of options for energy recovery from municipal solid waste in India using the hierarchical analytical network process. Energy 2013, 59, 215-223. [CrossRef]

20. Haddad, B.; Liazid, A.; Ferreira, P. A multi-criteria approach to rank renewables for the Algerian electricity system. Renew. Energy 2017, 107, 462-472. [CrossRef]

21. Arsić, S.; Nikolić, D.; Mihajlović, I.; Fedajev, A.; Živković, Ž. A New Approach Within ANP-SWOT Framework for Prioritization of Ecosystem Management and Case Study of National Park Djerdap, Serbia. Ecol. Econ. 2018, 146, 85-95. [CrossRef]

22. Grošelj, P.; Hodges, D.; Stirn, L.Z. The environmental management problem of Pohorje, Slovenia: A new group approach within ANP-SWOT framework. J. Environ. Manag. 2015, 161, 106-112. [CrossRef] [PubMed] 
23. Gigović, L.J.; Pamučar, D.; Božnić, D.; Ljubojević, S. Application of the GIS-DANPMABAC multi-criteria model for selecting the location of wind farms: A case study of Vojvodina, Serbia. Renew. Energy 2017, 103, 501-521. [CrossRef]

24. Sevkli, M.; Oztekin, A.; Uysal, O.; Torlak, G.; Turkyilmaz, A.; Delen, D. Development of a fuzzy ANP based SWOT analysis for the airline industry in Turkey. Expert Syst. Appl. 2012, 39, 14-24. [CrossRef]

25. Gim, B.; Kim, J.W. Multi-criteria evaluation of hydrogen storage systems for automobiles in Korea using the fuzzy analytic hierarchy process. Int. J. Hydrogen Energy 2014, 39, 7852-7858. [CrossRef]

26. Karmaker, C.; Saha, M. Optimization of warehouse location through fuzzy multi-criteria decision making methods. Decis. Sci. Lett. 2015, 4, 315-334. [CrossRef]

27. Ashrafzadeh, M.; Rafiei, F.M.; Isfahani, N.M.; Zare, Z. Application of fuzzy TOPSIS method for the selection of warehouse location: A case study. Interdiscip. J. Cont. Res. Bus. 2012, 3, 655-671.

28. Sezer, F.; Özkan, B.A.L.I.; Gürol, P. Hazardous materials warehouse selection as a multiple criteria decision making problem. J. Econ. Bibliog. 2016, 3, 63-73.

29. Chatterjee, K.; Kar, S. Pattern Recognition and Machine Intelligence: An Induced Fuzzy Rasch-VIKOR Model for Warehouse Location Evaluation under Risky Supply Chain; Springer: Berlin/Heidelberg, Germany, 2013.

30. Dey, B.; Bairagi, B.; Sarkar, B.; Sanyal, S.K. A hybrid fuzzy technique for the selection of warehouse location in a supply chain under a utopian environment. Int. J. Manag. Sci. Eng. Manag. 2013, 8, 250-261. [CrossRef]

31. Emeç, S..; Akkaya, G. Stochastic AHP and fuzzy VIKOR approach for warehouse location selection problem. J. Enterp. Inf. Manag. 2018, 31, 950-962. [CrossRef]

32. Eko Saputro, T.; Daneshvar Rouyendegh, B. A hybrid approach for selecting material handling equipment in a warehouse. Int. J. Manag. Sci. Eng. Manag. 2016, 11, 34-48. [CrossRef]

33. Erkan, T.E.; Can, G.F. Selecting the best warehouse data collecting system by using AHP and FAHP methods. Tech. Gaz. 2014, 21, 87-93.

34. Burinskienè, A. The efficiency evaluation when RFID is used in warehouses. J. Manag. 2015, 26, 7-15.

35. Bu, F. A Data mining framework for massive RFID data based on apriori algorithm. J. Phys. Conf. Ser. 2018, 1087, 022020. [CrossRef]

36. Cebeci, U. Fuzzy AHP-based decision support system for selecting ERP systems in textile industry by using balanced scorecard. Expert Syst. Appl. 2009, 36, 8900-8909. [CrossRef]

37. Yuksel, I.; Dagdeviren, M. Using the analytic network process (ANP) in a SWOT analysis-A case study for a textile firm. Inf. Sci. 2007, 177, 3364-3382. [CrossRef]

38. Rao, R.V.; Rajesh, T.S. Software selection in manufacturing industries using a fuzzy multiple criteria decision making method, PROMETHEE. Intell. Inf. Manag. 2009, 1, 159. [CrossRef]

39. Cochran, J.K.; Chen, H.N. Fuzzy multi-criteria selection of object-oriented simulation software for production system analysis. Comput. Oper. Res. 2005, 32, 153-168. [CrossRef]

40. Büyüközkan, G.; Kahraman, C.; Ruan, D. A fuzzy multi-criteria decision approach for software development strategy selection. Int. J. Gen. Syst. 2004, 33, 259-280. [CrossRef]

41. Etaati, L.; Sadi-Nezhad, S.; Makue, A. Using fuzzy group analytical network process and ISO 9126 quality model in software selection: A case study in e-learning systems. J. Appl. Sci. 2011, 11, 96-103. [CrossRef]

42. Kang, D.; Jang, W.; Park, Y. Evaluation of e-commerce websites using fuzzy hierarchical TOPSIS based on ES-QUAL. Appl. Soft Comput. 2016, 42, 53-65. [CrossRef]

43. Chou, W.C.; Cheng, Y.P. A hybrid fuzzy MCDM approach for evaluating website quality of professional accounting firms. Expert Syst. Appl. 2012, 39, 2783-2793. [CrossRef]

44. Sun, C.C.; Lin, G.T. Using fuzzy TOPSIS method for evaluating the competitive advantages of shopping websites. Expert Syst. Appl. 2009, 36, 11764-11771. [CrossRef]

45. Buyukozkan, G.; Cifci, G. A novel hybrid MCDM approach based on fuzzy DEMATEL, fuzzy ANP and fuzzy TOPSIS to evaluate green suppliers. Expert Syst. Appl. 2012, 39, 3000-3011. [CrossRef]

46. Kahraman, C.; Yasin Ateş, N.; Çevik, S.; Gülbay, M.; Ayça Erdoğan, S. Hierarchical fuzzy TOPSIS model for selection among logistics information technologies. J. Enterp. Inf. Manag. 2007, 20, 143-168. [CrossRef]

47. Babaesmailli, M.; Arbabshirani, B.; Golmah, V. Integrating analytical network process and fuzzy logic to prioritize the strategies-a case study for tile manufacturing firm. Expert Syst. Appl. 2012, 39, 925-935. [CrossRef]

48. Reihanian, A.; Zalina, B.M.; Kahrom, E.; Hin, T.W. Sustainable tourism development strategy by SWOT analysis: Boujagh National Park, Iran. Tour. Manag. Perspect. 2012, 4, 223-228. [CrossRef] 
49. Ghorbani, A.; Raufirad, V.; Rafiani, P.; Azadi, H. Ecotourism sustainable development strategies using SWOT and QSPM model: A case study of Kaji Namakzar wetland, south Khorsan Province, Iran. Tour. Manag. Perspect. 2015, 16, 290-297. [CrossRef]

50. Kheirkhah, A.; Babaeianpour, M.; Bassiri, P. Development of a hybrid method based on fuzzy PROMETHEE and ANP in the framework of SWOT analysis for strategic decisions. Int. J. Basic Appl. Sci. 2014, 8, 504-515.

51. Rauch, P. SWOT analyses and SWOT strategy formulation for forest owner cooperations in Austria. Eur. J. For. Res. 2007, 126, 413-420. [CrossRef]

52. Dana, B.G. SWOT analysis to improve quality management production. Procedia-Soc. Behav. Sci. 2012, 62, 319-324. [CrossRef]

53. Stanujkic, D.; Zavadskas, E.K.; Karabasevic, D.; Smarandache, F.; Turskis, Z. The use of the pivot pairwise relative criteria importance assessment method for determining the weights of criteria. Rom. J. Econ. Forecast 2017, 20, 116-133.

54. Stević, Ž.; Pamučar, D.; Kazimieras Zavadskas, E.; Ćirović, G.; Prentkovskis, O. The selection of wagons for the internal transport of a logistics company: A novel approach based on rough BWM and rough SAW methods. Symmetry 2017, 9, 264. [CrossRef]

55. Stojčić, M.; Pamučar, D.; Mahmutagić, E.; Stević, Ž. Development of an ANFIS Model for the Optimization of a Queuing System in Warehouses. Information 2018, 9, 240. [CrossRef]

56. Mulalić, E.; Stević, Ž.; Božičković, Z.; Vasiljević, M.; Sremac, S. Decomposition and centralization of warehouse systems in order to rationalize material flows. In Proceedings of the International conference transport and logistics-til 2017, Niš, Serbia, 25-26 May 2017; pp. 83-90.

57. Stević, Ž.; Mulalić, E.; Đalić, I.; Vasiljević, N. SWOT analysis of logistics system in company of the paper production. In Proceedings of the International May Conference on Strategic Management-IMKSM17, Bor, Serbia, 19-21 May 2017; pp. 59-69.

58. Stević, Ž.; Mulalić, E.; Božičković, Z.; Vesković, S.; Đalić, I. Economic analysis of the project of warehouse centralization in the paper production company. Serbian J. Manag. 2018, 13, 47-62. [CrossRef]

59. Radović, D.; Stević, Ž. Evaluation and selection of KPI in transport using SWARA method. Transp. Logist. 2018, 44, 60-68.

60. Wątróbski, J.; Jankowski, J.; Ziemba, P.; Karczmarczyk, A.; Zioło, M. Generalised framework for multi-criteria method selection. Omega 2018. [CrossRef]

61. Pei, L.; Jin, F. Two hesitant multiplicative decision-making algorithms and their application to fog-haze factor assessment problem. Algorithms 2018, 11, 154. [CrossRef]

62. Bashir, Z.; Rashid, T.; Watróbski, J.; Sałabun, W.; Malik, A. Hesitant probabilistic multiplicative preference relations in group decision making. Appl. Sci. 2018, 8, 398. [CrossRef]

63. Shao, S.; Zhang, X.; Li, Y.; Bo, C. Probabilistic single-valued (interval) neutrosophic hesitant fuzzy set and its application in multi-attribute decision making. Symmetry 2018, 10, 419. [CrossRef]

64. Faizi, S.; Rashid, T.; Sałabun, W.; Zafar, S.; Wątróbski, J. Decision making with uncertainty using hesitant fuzzy sets. Int. J. Fuzzy Syst. 2018, 20, 93-103. [CrossRef]

65. Xu, Y.; Shang, X.; Wang, J.; Wu, W.; Huang, H. Some q-Rung dual hesitant fuzzy heronian mean operators with their application to multiple attribute group decision-making. Symmetry 2018, 10, 472. [CrossRef]

66. Zhang, X.; Xu, Z.; Liu, M. Hesitant trapezoidal fuzzy QUALIFLEX method and its application in the evaluation of green supply chain initiatives. Sustainability 2016, 8, 952. [CrossRef]

67. Roy, B. Paradigms and Challenges. In Multiple Criteria Decision Analysis. State of the Art Surveys, 2nd ed.; Greco, S., Ehrgott, M., Figueira, J.R., Eds.; Springer: New York, NY, USA, 2016; pp. 19-39.

68. Ziemba, P. NEAT F-PROMETHEE-A new fuzzy multiple criteria decision making method based on the adjustment of mapping trapezoidal fuzzy numbers. Expert Syst. Appl. 2018, 110, 363-380. [CrossRef]

(C) 2018 by the authors. Licensee MDPI, Basel, Switzerland. This article is an open access article distributed under the terms and conditions of the Creative Commons Attribution (CC BY) license (http:/ / creativecommons.org/licenses/by/4.0/). 